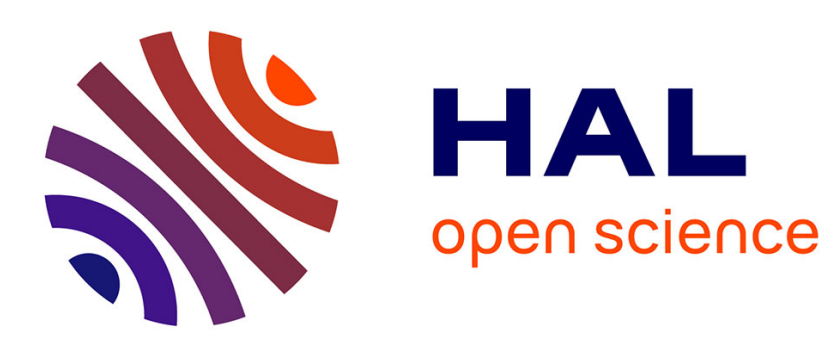

\title{
Effect of Pickering stabilization on radical entry in emulsion polymerization
}

\author{
Barthélémy Brunier, Nida Sheibat-Othman, Yves Chevalier, Elodie \\ Bourgeat-Lami
}

\section{- To cite this version:}

Barthélémy Brunier, Nida Sheibat-Othman, Yves Chevalier, Elodie Bourgeat-Lami. Effect of Pickering stabilization on radical entry in emulsion polymerization. AIChE Journal, 2018, 64 (7), pp.2612-2624. 10.1002/aic.16159 . hal-02139828

\section{HAL Id: hal-02139828 \\ https://hal.science/hal-02139828}

Submitted on 6 Dec 2020

HAL is a multi-disciplinary open access archive for the deposit and dissemination of scientific research documents, whether they are published or not. The documents may come from teaching and research institutions in France or abroad, or from public or private research centers.
L'archive ouverte pluridisciplinaire $\mathbf{H A L}$, est destinée au dépôt et à la diffusion de documents scientifiques de niveau recherche, publiés ou non, émanant des établissements d'enseignement et de recherche français ou étrangers, des laboratoires publics ou privés. 


\title{
Effect of Pickering stabilization on radical entry in emulsion polymerization
}

\author{
Barthélémy Brunier, ${ }^{1}$ Nida Sheibat-Othman, ${ }^{1, *}$ Yves Chevalier, ${ }^{1}$ Élodie Bourgeat-Lami ${ }^{2}$ \\ ${ }^{1}$ Université de Lyon, Université Claude Bernard Lyon 1, CNRS, UMR 5007, LAGEP, 43 bd 11 \\ Novembre 1918, F-69622 Villeurbanne, France \\ ${ }^{2}$ Université de Lyon, Université Claude Bernard Lyon 1, CPE Lyon, CNRS, UMR 5265, Chemistry, \\ Catalysis, Polymers and Processes (C2P2), 43 bd 11 Novembre 1918, F-69616 Villeurbanne, France \\ * Corresponding author: nida.othman@univ-lyon1.fr
}

\begin{abstract}
The production of latexes stabilized by solid particles, so-called Pickering stabilizers, has attracted considerable attention due to its benefits, including the enhanced mechanical properties of the polymer films. Clays for instance were found to enhance particle stabilization in emulsion polymerization, in a comparable way to conventional surfactants. Their concentration thus determines the polymer particles size and number, and consequently the reaction rate. In this work, we investigate the impact of the presence of such rigid and big platelets at the polymer particle's surface on radical exchange between the aqueous phase and the polymer particles. It was found for the system underhand, that the average number of radicals per particle $(\bar{n})$ was independent of the stabilizer layer. Therefore, a radical capture model independent of the clay concentration could be used to simulate reactions involving different clay concentrations and predict the evolution of the monomer conversion, particle size, and $\bar{n}$.
\end{abstract}

Keywords: Pickering emulsion polymerization; modeling; clay; radical capture; particle growth. 


\section{Introduction}

Polymer/clay nanocomposites. Polymer/clay nanocomposites can be elaborated by means of in situ free radical emulsion polymerization by reacting organic monomers in the presence of inorganic colloidal particles as the sole stabilizers with no chemical modifications. ${ }^{1-3}$ Laponite ${ }^{\circledR}$ clay has been first used in emulsion polymerization with addition of surfactant. In other previous works, the clay has been functionalized with either cationic initiators or cationic monomers through ion exchange, or by the reaction of the edge-hydroxyls with suitable organosilane molecules in order to ensure its strong adsorption to the polymer colloids. ${ }^{4-7}$ In this case, stable aqueous colloidal suspensions of polymer/Laponite particles with diameters in the range $50-150 \mathrm{~nm}$ were obtained consisting of a polymer core surrounded by an outer shell of clay platelets. It has been subsequently disclosed that bare (non-modified) Laponite particles could be used in emulsion polymerization without addition of surfactant. $^{8-10}$ In such surfactant-free heterophase polymerizations, known as "Pickering emulsion polymerization", the adsorption of clay stabilizes the dispersion of polymer particles. However, as clay adsorption changes the surface properties of the polymer particles, their interaction with charged free radicals and the radical entry into polymer particles might be affected by the presence of adsorbed clay. The objective of this work is to investigate the impact of the stabilizer layer on radical exchange between the aqueous phase and the polymer particles through combined experimental investigation and modeling of the emulsion polymerization process.

Modeling Pickering emulsion polymerization. Modeling the polymer properties in conventional emulsion polymerization systems requires dynamic modeling of the molecular weight distribution (MWD) and the particle size distribution (PSD) along the polymerization process. Modeling the PSD requires the different phenomena taking place during the polymerization, including nucleation, coagulation and particle growth events, to be taken into account. When changing the process for 
Pickering stabilization, only the PSD model is presumed to be changed owing to the altered mechanisms of stabilization, nucleation and mass transfer. The MWD might change through indirect ways, but its classical model for emulsifier-based emulsion polymerization remains valid. In order to investigate the effect of Pickering stabilization on radical exchange, it is helpful to design experimental conditions such that the PSD changes are solely due to particle growth, while avoiding particle (re)nucleation and coagulation by ensuring efficient stabilization. Moreover, maintaining the polymer particles saturated with monomer allows maintaining constant the propagation and termination rate coefficients, as the diffusion coefficients remain constant. ${ }^{11}$ Therefore, particle growth becomes only dependent of the average number of radicals per particle, $\bar{n}$, which in turn is affected by radical entry and desorption rates inside and out of the particles. Radical desorption is usually assumed independent of the stabilization nature as it only concerns monomeric and small oligomeric radicals issued from radical transfer to monomers taking place inside the particles; the species of relevance usually contain one to two monomer units, depending on the monomer solubility in water, and they are non-charged. ${ }^{12,13}$ The desorption models of conventional emulsion polymerization can hence be used in modeling Pickering emulsion polymerization. Any variation in $\bar{n}$ due to the particles stabilization nature can thus be attributed to changes in the radical capture by particles.

Radical capture. Radical capture concerns radicals issued from initiator decomposition and propagation in water, which may be long and charged, if for instance a persulfate initiator is used. For conventional emulsifiers (e.g. anionic stabilizers such as sodium lauryl sulfate or nonionic ones like TritonX-405 ${ }^{14}$ ), the emulsifier layer on the surface of the polymer particles is considered not to affect radical entry. ${ }^{15}$ However, for some specific cases, the stabilizing layer was reported to affect radical entry as for instance in the case of the nonionic NP30 polyoxyethylene nonylphenol surfactant (with 30 EO units). ${ }^{16,17}$ Similar conclusions were reported for the reactive surfactant sodium dodecyl allyl 
sulfosuccinate. ${ }^{18}$ Some polymeric surfactants were also reported to impact radical entry (e.g. copolymers of acrylic acid and styrene, ${ }^{19}$ copolymers of styrene and styrene sulfonate, ${ }^{20}$ and to a lower extent poly(acrylic acid) ${ }^{21}$ ), especially when the charge of the entering radicals was different from that of the polyelectrolyte surfactant. ${ }^{22}$ These previous studies indicate that it is necessary to verify whether the adsorbed layer of clay platelets on the surface of the polymer particles can act as a barrier for diffusion against the entering radicals, in order to determine the most appropriate radical entry model for the present system.

Objectives. In this work, Laponite clay was used as stabilizer in surfactant-free Pickering emulsion polymerization. The Laponite platelets are rigid particles with overall dimensions ( $1 \mathrm{~nm}$ in thickness and $25 \mathrm{~nm}$ in diameter) significantly bigger than the head group size of conventional surfactants. Moreover, when dispersed into water, a strongly negative charge (700 elementary charges per clay particle) appears on their basal faces (due to the release of the $\mathrm{Na}^{+}$ions from their surface) and the weakly positive charge on the rim of the disks due to protonation of the $\mathrm{OH}$ groups is compensated by adsorbed pyrophosphate anions. ${ }^{23,24}$ Our objective is thus to check whether the rate of radical capture into the polymer particles is affected either mechanically by the dimension/rigidity of the clay platelets located at the particle surface or by the presence of surface charges. The concentration of clay adsorbed on the polymer particles has been estimated in our previous works where the clay was found to form multilayers on the particle surface. ${ }^{25,26}$ Semi-continuous ab initio Pickering emulsion polymerization of styrene in the presence of Laponite was considered under saturation of the polymer particles with monomer, and under conditions such that neither nucleation nor coagulation was taking place. Different clay concentrations were considered for an assessment of the effect of the surface charge density. These results were supported by seeded experiments. 


\section{Materials and methods}

Materials. The monomer, styrene (Acros Organics, 99\% extra pure, stabilized) was stored in a fridge until used. Potassium persulfate (KPS, Sigma-Aldrich, minimum 99\%) was used as initiator. Laponite ${ }^{\circledR}$ RDS (a synthetic clay from BYK Additives Ltd) was used as stabilizer. Deionized water with a resistivity value of $18 \mathrm{M} \Omega \mathrm{cm}$ was used throughout the work.

Seed preparation. The seed was prepared batchwise. The clay $\left(1 \mathrm{~g} \mathrm{~L}^{-1}\right)$ was mixed with water $(800 \mathrm{~g})$ for $30 \mathrm{~min}$ at ambient temperature. This mixture was then degassed using nitrogen in the reactor, and heated to $70{ }^{\circ} \mathrm{C}$ using a thermostated bath. Then, $200 \mathrm{~g}$ of styrene was added and the polymerization was initiated by adding $1.6 \mathrm{~g}$ of potassium persulfate (KPS). During the reaction, the stream of nitrogen was moved upwards off the reaction medium to the top of the reactor to maintain saturation of the gaseous atmosphere with nitrogen.

Seeded polymerization experiments. Part of the above-described seed ( $200 \mathrm{~g})$ was added to the reactor with $640 \mathrm{~g}$ of deionized water with different amounts of clay and the dispersion was allowed to equilibrate for $12 \mathrm{~h}$ (to allow adsorption of clay on the polymer particles) at ambient temperature under stirring at $200 \mathrm{rpm}$. Then, $40 \mathrm{~g}$ of styrene were added and the seed particles were allowed to swell for 1 h. The dispersion was then heated to $70{ }^{\circ} \mathrm{C}$ and degassed, and the initiator was added to start the polymerization. At about $50 \%$ conversion (as determined by calorimetry), $160 \mathrm{~g}$ of monomer was added semi-continuously at a flow rate of $0.02 \mathrm{~g} \mathrm{~s}^{-1}$ (under starved conditions). At the end of the reaction, a batch polymerization period of 30 min was conducted to raise the conversion of the monomer above $90 \%$.

$A b$ initio semi-continuous polymerization experiments. The polymerization reaction was performed in two successive periods: a first batch period for particle nucleation (formation of seed particles) 
followed by a second semi-batch period for particles growth. The clay powder was firstly dispersed in $800 \mathrm{~g}$ of water for $30 \mathrm{~min}$ under stirring in the reactor at ambient temperature. Different amounts of clay were used in the different experiments, varying from 0.1 to $10 \mathrm{~g} \mathrm{~L}^{-1}$. The resulting suspension was degassed using nitrogen flow and heated to $70^{\circ} \mathrm{C}$. Then, $40 \mathrm{~g}$ of styrene was added and the polymerization was initiated by adding the initiator. After about $30 \mathrm{~min}$, the semi-continuous period was started by adding $160 \mathrm{~g}$ of monomer at a flow rate of $0.02 \mathrm{~g} \mathrm{~s}^{-1}$ (under saturation conditions).

All experiments were done in a $1 \mathrm{~L}$ reactor equipped with mechanical stirring at $400 \mathrm{rpm}$ using a three blades Bohlender propeller, with the same concentration of initiator. Samples were withdrawn at specific time intervals to measure the solids content (SC, i.e. mass fraction of solid) using a thermogravimetric balance and the particle size using dynamic light scattering (DLS using NanoZS instrument from Malvern ${ }^{\circledR}$ ). The solids content was used to calculate the amount of polymer and the monomer conversion, after subtracting the mass of clay and initiator. Combination of both measurements allowed the calculation of the particle number density. As previously reported, ${ }^{25}$ the ratio of the area of clay platelets' faces to the polymer particles area could be calculated to get an estimate of the surface coverage of the latex particles by the clay.

Dynamic light scattering measurements. As modeling results are highly relying on the particle size distribution measured by DLS, combined with the solids content, it is important to highlight a few issues. The particle number density (particles per unit volume/diameter) can be characterized by the mean particle size (that can be assumed to be accurately determined by DLS) and the width of the PSD, that may be subject to statistical errors and to systematic bias. ${ }^{27}$ Statistical errors are coming from lack of accuracy of the recorded signal and they can be minimized by recording a high signal-to-noise ratio. The systematic bias comes from the conversion of the recorded autocorrelation function of scattered light into PSD and as it is systematic, it cannot be estimated by statistical analysis of repeated 
measurements. Indeed, the determination of PSD by means of inverse Laplace transform of the "illconditioned" autocorrelation function requires a mathematical regularization in the CONTIN software such that the PSD cannot assume negative values. ${ }^{28}$ The consequence is the broadening of the PSD, that is estimated by Malvern to be about $10-15 \%$ for monodisperse samples. A comparative study of the PSD of latex dispersions of various sizes with narrow PSD measured by various techniques allows to conclude that PSD broadening by DLS is of the order of $23 \%$ compared to electron microscopy image analysis. $^{29}$

\section{Modeling}

The equations for the models relating the particle size distribution, average number of radicals per particle and radical capture are presented below. The other necessary equations are given in the appendix.

\section{Polymer particles population balance}

The comprehensive particle size distribution model in emulsion polymerization takes into account the

particles formation by nucleation, their growth by polymerization and the coagulation mechanisms. ${ }^{30}$ Assuming stable particles without nucleation of new particles leads to the following balance:

$$
\frac{\partial F(r, t)}{\partial t}+\frac{\partial(F(r, t) G(r, t))}{\partial r}=0
$$

where $F(r, t)$ is the number density of particles of radius between $r$ and $r+\delta r$ at time $t$, and $G(r, t)$ is the growth rate of particles of size $r$ given by:

$$
G(r, t)=\frac{d r}{d t}=\frac{k_{p}[M]_{p} M_{W} \bar{n}(r, t)}{4 \pi \rho_{m} N_{A} r^{2}}
$$


where $\bar{n}(r, t)$ is the average number of radicals per particle of size $r, M_{W}$ the monomer molecular weight, $\rho_{m}$ the monomer density, $k_{p}$ the propagation rate coefficient, $[M]_{p}$ the concentration of monomer in the polymer particles (maintained constant during the monomer saturated period presently studied) and $N_{A}$ is the Avogadro's number. Most of the polymer is produced inside the polymer particles even though the initiation of polymer chains takes place in water. ${ }^{31}$ Therefore, the polymerization rate in the polymer particles per unit volume of latex is given by:

$$
R_{p_{p}}(t)=\frac{k_{p}[M]_{p}}{N_{A}} \int_{0}^{\infty} \bar{n}(r, t) F(r, t) d r
$$

The number of monomer-swollen polymer particles per unit volume of latex is given by $N=$ $\int_{0}^{\infty} F(r, t) d r$, and was also considered constant in this study.

\section{Average number of radicals per particle}

The first quantitative theory for the average number of radicals per particle, $\bar{n}$, was developed by Smith and Ewart ${ }^{31}$ based on the model proposed by Harkins. ${ }^{32}$ Based on their classification of $\bar{n}$, two limits of the PSD models were developed later on: The zero-one model and the pseudo-bulk model. In the zeroone model, particles may contain only one growing radical, as the entry of a second radical into a latex particle results in an instantaneous termination reaction. ${ }^{33}$ Therefore, the average number of radicals per particle is less than one. As an extension to this model, the 0-1-2 model was proposed for vinyl acetate polymerization $^{34}$ and the $0-1-2-3$ for starved semi-continuous emulsion polymerizations. ${ }^{35}$ In the pseudo-bulk model, particles contain radicals that can coexist for a significant period. ${ }^{36}$

In the present work, the experimental estimations indicated big particles $\left(d_{p}>200\right)$ and $\bar{n}>1$ in most experiments. Under these conditions, the $0-1$ model is not valid. The condition of validity of the pseudobulk model is $\bar{n} \gg 1$, which is actually not met in all experiments. However, the pseudo-bulk model 
appears to be the best choice to approximate the behavior of the system for the different clay concentrations. Indeed, implementing the detailed Smith-Ewart equations accounting for particles containing a distribution of radicals would involve a tremendous calculation time and a specific model of the termination rate coefficients. The pseudo-bulk balance equation reads:

$$
\frac{\partial \bar{n}(r, t)}{\partial t}=\rho-R_{d e s}(r, t)-2 c(r) \bar{n}(r, t)^{2}
$$

where $\rho$ is the rate of radical capture, $R_{\text {des }}$ the rate of radical exit and $c(r)$ is the pseudo-first order termination rate coefficient between two chains given by:

$$
c(r)=\frac{k_{t_{p}}}{N_{A} v_{s}}
$$

with $k_{t_{p}}$ the termination rate coefficient and $v_{s}$ the volume of swollen polymer particles. Equation 4 is correct when $\bar{n}$ forms a Poisson distribution, which is the case for high values of $\bar{n} .^{36}$

\section{Clay partitioning}

The clay platelets constitute the main source of stabilization in the present system. They adsorb on the surface of the polymer particles and increase their surface charge, thus improving their stability against coagulation. Moreover, the formation of a rigid coating of clay platelets around the polymer particles prevents the latex particles from close contact and coagulation.

As the objective of this work is to investigate the effects of the clay layer on radical capture, it is important to evaluate the amount of clay on the surface of the polymer particles. It was previously observed, using Quartz Crystal Microbalance, that the adsorption of Laponite RDS clay on the surface of polystyrene films was fast. ${ }^{25}$ Moreover, multilayer arrangement of adsorbed clay platelets on the surface of the polymer particles was observed by transmission electron microscopy and titration of clay 
by Inductively Coupled Plasma-Optical Emission Spectroscopy (ICP-OES). Such measurements showed that there was almost no residual clay in the aqueous phase for all clay concentrations studied in this work. Therefore, the concentration of clay on the polymer particles could simply be taken as the total clay concentration introduced into the reactor.

\section{Radical capture mechanisms}

Different mechanisms have been proposed in the literature to describe radical capture, which is due to the wide range of explored reaction conditions, e.g. monomer solubility, reaction temperature, particle size and type of surfactant. In order to allow easier comparison between the different models and highlight similarities among them, some models have been slightly reformulated in the subsequent paragraph (e.g. all models are presented in diameter).

The rate of radical entry can generally be written under the following form:

$$
\rho=k_{e}[R]_{w}
$$

with $k_{e}$ the rate coefficient for radical entry from the aqueous phase into particles and $[R]_{w}$ the concentration of radicals in the aqueous phase.

The proposed mechanisms can then be classified in terms of $k_{e}$ as follows:

1) Diffusion-controlled radical capture mechanism: In the original model proposed by Smith and Ewart, the rate of radical entry into a polymer particle $(\rho)$ is given by the rate of diffusion of free radicals from the aqueous phase with a linear dependency on the particle diameter. ${ }^{31}$ They thus used the

Smoluchowski equation for the radical entry rate coefficient. ${ }^{37}$ When an efficiency factor $\left(f_{e}\right)$ is added to this coefficient, it takes the following form $\left(f_{e}=1\right.$ in the model proposed by Smith and Ewart): 


$$
k_{e(i)}(r)=2 \pi d_{p} N_{\mathrm{A}} D_{\mathrm{w}(i)} f_{e}
$$

where $D_{\mathrm{w}(i)}=\frac{k_{B} T}{6 \pi \eta r_{i}}$ is the diffusion coefficient of radicals of length $i\left(D_{\mathrm{w}(z)}=5.1 \times 10^{-8} \mathrm{dm}^{2} \mathrm{~s}^{-1}\right.$ for $i=z)$.

Table 1: Radical efficiency capture factor $f_{e}$ in the diffusion-controlled mechanism

\begin{tabular}{|c|c|}
\hline Reference & $f_{e}$ \\
\hline Smith and Ewart (1948) & $f_{\mathrm{e}}=1$ \\
\hline \multirow{4}{*}{ Hansen and Ugelstad (1978) } & 1 \\
\hline & $f_{\mathrm{e}}=\frac{m \cdot \exp \left(z_{\alpha}\right) D_{\mathrm{w}}}{\frac{\left.\tilde{X}_{\mathrm{p}} \cdot \operatorname{coth}\left(\tilde{X}_{\mathrm{p}}\right)-1\right) D_{\mathrm{p}}}{(\tilde{x}}+W}$ \\
\hline & $\tilde{X}=\underline{d} \sqrt{k_{\mathrm{p}}[\mathrm{M}]_{\mathrm{p}}}+\frac{k_{\mathrm{tp}} n(r)}{\mathrm{X}}$ \\
\hline & $X_{\mathrm{p}}=\overline{2} \sqrt{\frac{D_{\mathrm{p}}}{D_{\mathrm{A}} v D_{\mathrm{p}}}}, z_{\alpha}=\frac{\overline{k_{\mathrm{B}} T}}{2}, W=\frac{-}{2} \int_{0} \exp \left(\overline{k_{\mathrm{B}} T}\right) \overline{\left(\frac{d}{2}+L\right)^{2}}$ \\
\hline \multirow{2}{*}{ Coen et al. (1998) } & $f=\left\{\frac{1}{i^{1 / 2}}\right.$ \\
\hline & $J_{e}=\left\{\begin{array}{rr}0, & \text { else } \\
1, & \text { for exited radicals }\end{array}\right.$ \\
\hline \multirow{2}{*}{$\begin{array}{l}\text { Herrera-Ordóñez and R. Olayo } \\
(2000)\end{array}$} & $=\frac{k_{\mathrm{p}}[\mathrm{M}]_{\mathrm{p}}+k_{\mathrm{tp}} n(r)(n(r)-1) /\left(v N_{\mathrm{A}}\right)}{2}$ \\
\hline & $f_{\mathrm{e}}=\overline{k_{0}+k_{\mathrm{p}}[\mathrm{M}]_{\mathrm{p}}+k_{\mathrm{tp}} n(r)(n(r)-1) /\left(v N_{\mathrm{A}}\right)}$ \\
\hline \multirow{2}{*}{ Nomura et al. (2005) } & $f_{\mathrm{e}}=\frac{k_{\mathrm{p}}[\mathrm{M}]_{\mathrm{p}}+k_{\mathrm{tp}} n(r) /\left(v N_{\mathrm{A}}\right)}{u}$ \\
\hline & $\mathrm{e}_{\mathrm{e}}=\overline{k_{0}+k_{\mathrm{p}}[\mathrm{M}]_{\mathrm{p}}+k_{\mathrm{tp}} n(r) /\left(v N_{\mathrm{A}}\right)}$ \\
\hline Hernández and Tauer (2007) & $f_{\mathrm{e}}=p \frac{\pi}{6} d^{3} N+1$ \\
\hline
\end{tabular}

In the diffusion-controlled model, the capture rate is thus proportional to the particle diameter. This model predicted in some cases much faster rates than in experiments. ${ }^{38}$ Therefore, a radical capture efficiency term was added to this model, first by Hansen and Ugelstad (1976) to account for the fact that not every radical-particle collision leads to a radical absorption event. They proposed $f_{e}=U / W$, with $U$ the reversibility factor accounting for the balance of absorption and desorption and $W$ the stability ratio accounting for electrostatic repulsions between charged radicals in the aqueous phase and particles (see Table 1) ${ }^{39}$ Note that in this model, $f_{e}$ depends on the oligoradical size through the parameters $m, D_{w}$, $D_{p}$ (its dependency on $i$ is not indicated in the table for brevity). Herrera-Ordóñez and Olayo (2000) 
used the model of Hansen and Ugelstad to estimate monomeric radical entry efficiency, but proposed a simplified model for polymeric radical entry efficiency. ${ }^{40}$ Hernández and Tauer (2007) proposed a radical entry model accounting for the effect of the overall polymer content on radical entry. ${ }^{41}$ On the same basis, several types of limitations to radical entry were considered, leading to several expressions of efficiency terms. ${ }^{42,43}$ Table 1 shows few expressions of $f_{e}$ that have been proposed.

In this model, the radical capture rate coefficient $k_{\mathrm{e}}$ increases with increasing the particle size. A quick investigation of the models in Table 1 shows that for big particle sizes, the value of $f_{\mathrm{e}}$ becomes close to one, and thus they become similar to the Smith and Ewart model (where $f_{\mathrm{e}}=1$ ). For instance, the model of Nomura et al. gives $f_{e} \approx 1$ for big particles due to the low desorption rate coefficient, $k_{0}$, for styrene considered here. This phenomenon has also been observed by Herrera-Ordóñez and Olayo who noted that the radical capture efficiency was lower for shorter polymeric radicals and smaller particles, leading to values between $f_{e}=10^{-9}$ and $f_{e}=1$ for styrene polymerization. For instance, they estimated $f_{e} \cong 10^{-3}$ for radicals of length $i=2$ and $d_{p}=10 \mathrm{~nm}$, while $f_{e} \cong 1$ for $i=4$ and $d_{p}=100 \mathrm{~nm} .{ }^{40} \mathrm{In}$ the model of Hansen and Ugelstad, increasing $W$, representing the stability of radicals in the aqueous phase, reduces their capture efficiency by the particles. This model has been used by Harada et al. (1972) to distinguish between particles and micelles, where a 100 times lower capture efficiency factor was measured for micelles than for particles, as the difference in size alone could not explain the observations. ${ }^{44}$ This could be due to the low residence time of radicals inside micelles that prevented propagation before exiting the micelles again. Indeed, radicals are considered to be irreversibly captured by particles and/or micelles only if they react therein. Hernández and Tauer suggested that the polymer volume fraction might affect radical collision kinetics. They predicted a radical capture efficiency close to one for polymer volume fractions lower than $10^{-2}$ but the efficiency increased importantly when the 
polymer content was increased (up to 10 for $10 \%$ volume fraction). This consequently leads to $k_{\mathrm{e}}$ values higher than those of Smith and Ewart.

2) Collision-controlled radical capture mechanism: In this mechanism, radical capture is considered to be proportional to the particle surface area in interval I (i.e. for small particles) (Gardon, 1968): ${ }^{45}$

$$
\rho=\frac{1}{4} \pi d_{p}^{2} L N_{A} R
$$

where $\left(L=\sqrt{2 D_{w} t_{\text {prec }}}\right)$ is the distance travelled by the entering radical, $t_{\text {prec }}$ is the radical precipitation time during which the radical may enter the particles and $R$ is the rate of radical generation given by $R=2 f k_{d}[I]$, where $f$ is the initiator efficiency, $k_{d}$ is the initiator decomposition coefficient and $[I]$ the initiator concentration. The precipitation time can be calculated by $t_{p r e c}=\frac{j_{c r}}{k_{p}[M]_{w}}$, where $j_{c r i t}$ is the degree of polymerization of a radical before precipitation in water and $[M]_{w}$ the concentration of monomer in water.

The authors estimated a degree of polymerization of vinyl acetate in water before precipitation of 53 monomer units. ${ }^{45}$ Adams et al. noted that this model predicted the presence of large oligoradicals of polymerization degree up to 50 monomer units that cannot be soluble in water. ${ }^{15}$ Penboss et al. (1986) indicated that this model gave $k_{e}$ values some ten orders of magnitude larger than their experimental results. $^{46}$

3) Colloidal-controlled radical capture mechanism: In this mechanism, the radical entry rate coefficient is set as the coagulation rate between a precursor radical and a latex particle (and is thus approximately proportional to the particle diameter) (Penboss et al. 1986): ${ }^{46}$ 


$$
k_{e}=\frac{k_{B} T N_{A}\left(d_{p}+d_{i}\right)^{2}}{3 \eta W d_{i} d_{p}}
$$

In this model, the radical stability ratio $W$ is calculated based on the DLVO theory. The diffusional Hansen and Ugelstad mechanism is also based on the stability ratio, but the colloidal model gives slightly lower $k_{e}$ values when implemented with the same value of stability ratio. In general, very high values of $W$, as those considered by Penboss et al., importantly reduce radical entry.

4) Propagation-controlled radical capture mechanism: Maxwell and Gilbert (1991) proposed to relate the entry rate to the average degree of polymerization of oligoradicals in the aqueous phase $(z)$ necessary in order to reach the required surface-activity for entry independently of the particle size or charge: ${ }^{47}$

$$
\rho=k_{p}[M]_{w}\left[I M_{z-1}^{\bullet}\right]_{w} \frac{N_{A}}{N}
$$

In this model, radical capture is independent of the particle size. The entry of $z$-mer radicals is assumed rapid, so that the generation of $z$-mer radicals from $(z-1)$-mer radicals by propagation reaction in the aqueous phase is the rate-controlling step. Oligoradicals of polymerization degree beyond the length $z$ are neglected in this model. Oligoradicals are no longer soluble when their polymerization degree exceeds $j_{c r}$; their precipitation in the aqueous phase leads to homogeneous nucleation of polymer particles. The critical length for entry $(z)$ and critical chain length in water $\left(j_{c r}\right)$ can be estimated based on thermodynamic grounds, ${ }^{16,20}$ or using the two-layer lattice model, ${ }^{48}$ which gives for styrene, $z=2-$ 3 and $j_{c r}=5 .{ }^{49} k_{e}$ can be extracted by combining equations 6 and 10, for the purpose of comparison with the other models, which gives:

$$
k_{\mathrm{e}}=k_{\mathrm{p}}[\mathrm{M}]_{\mathrm{w}} \frac{N_{\mathrm{A}}}{N} \frac{\left[\mathrm{IM}_{\mathrm{z}-1}^{\bullet}\right]_{\mathrm{w}}}{[\mathrm{R}]_{\mathrm{w}}}
$$


5) Surface layer hindrance: Yeliseyeva and Zuikov (1978) assumed that the stabilizer layer might hinder radical capture and that stabilizer displacement is required for radical capture ${ }^{50}$ Note that the models which depend on the stability of radicals in water (i.e., the diffusion model with the efficiency factor calculated by Ugelstad and Hansen (1976), or the colloidal model proposed by Penboss et al. (1986)), may be considered to reflect the effect of the surfactant layer on the radical capture rate, but the other models do not assume any hindrance due to the presence of surfactant.

All these models will be used to simulate the specific reaction conditions of the experiments presented above in order to evaluate the impact of the clay layer on the radical capture coefficient. Note that none of the available models relies on any adjustable parameters. Of course, a close analysis according to this method requires that a wide range of clay concentrations be investigated, as it has been done in the present work. In the same $a b$ initio reaction, the number of particles was maintained constant during the period considered for modeling, while in the seeded experiments the number of particles was the same for all experiments.

\section{Radical desorption}

A preliminary numerical analysis showed that desorption was negligible in the system underhand (for the big particles and high $\bar{n}$ obtained in this work, thus validating the assumption of the pseudo-bulk model). As a demonstration, if we consider equation 4 for particles of $200 \mathrm{~nm}$ in diameter, the termination rate at $70^{\circ} \mathrm{C}$ can be estimated by $2 c \bar{n}^{2}=150 \mathrm{~s}^{-1}$. The desorption rate calculated using the model of Hernandez and Tauer $2008{ }^{51}$ combined to the equilibrium radical desorption coefficient, $k_{0}$, proposed by Harada et al. $(1971)^{52}$ gives $k_{d e s} \bar{n}=6 \times 10^{-3} \mathrm{~s}^{-1}$ (see appendix). Under the stationary regime, where the number of radicals per particle stays constant $\left(k_{e}[R]_{w}-k_{d e s} \bar{n}-2 \frac{k_{t_{p}}}{N_{A} v_{s}} \bar{n}^{2}=0\right)$, it 
can be concluded that the radical entry rate is of the same order of magnitude as the termination rate and that the contribution of the desorption rate is negligible. Note that due to the negligible desorption rate, other desorption models led to the same conclusion.

\section{Results and discussion}

\section{Seeded experiments}

Seeded experiments were carried out with various concentrations of clay platelets. The initial number and size of particles were identical in all experiments. Figure 1 shows the evolution of the solids content in these experiments and the reaction rate estimated by calorimetry. It can be seen that the same amount of polymer was produced at the end of the reaction in all experiments and the reaction rate was identical in all experiments. This indicates that there was no effect of clay concentration on $\bar{n}$, and thus on radical capture.

It is however important to investigate radical exchange also in ab initio experiments. Indeed, the behavior of the clay adsorption may be different if it was incorporated since the nucleation of particles, where it might be anchored more strongly and thus affect radical capture differently than in seeded experiments. However, varying the clay concentration during the formation of the seed leads to the nucleation of a different number of particles with different sizes. Thus, there is a need to employ advanced modeling to isolate the effect of clay on radical capture. 

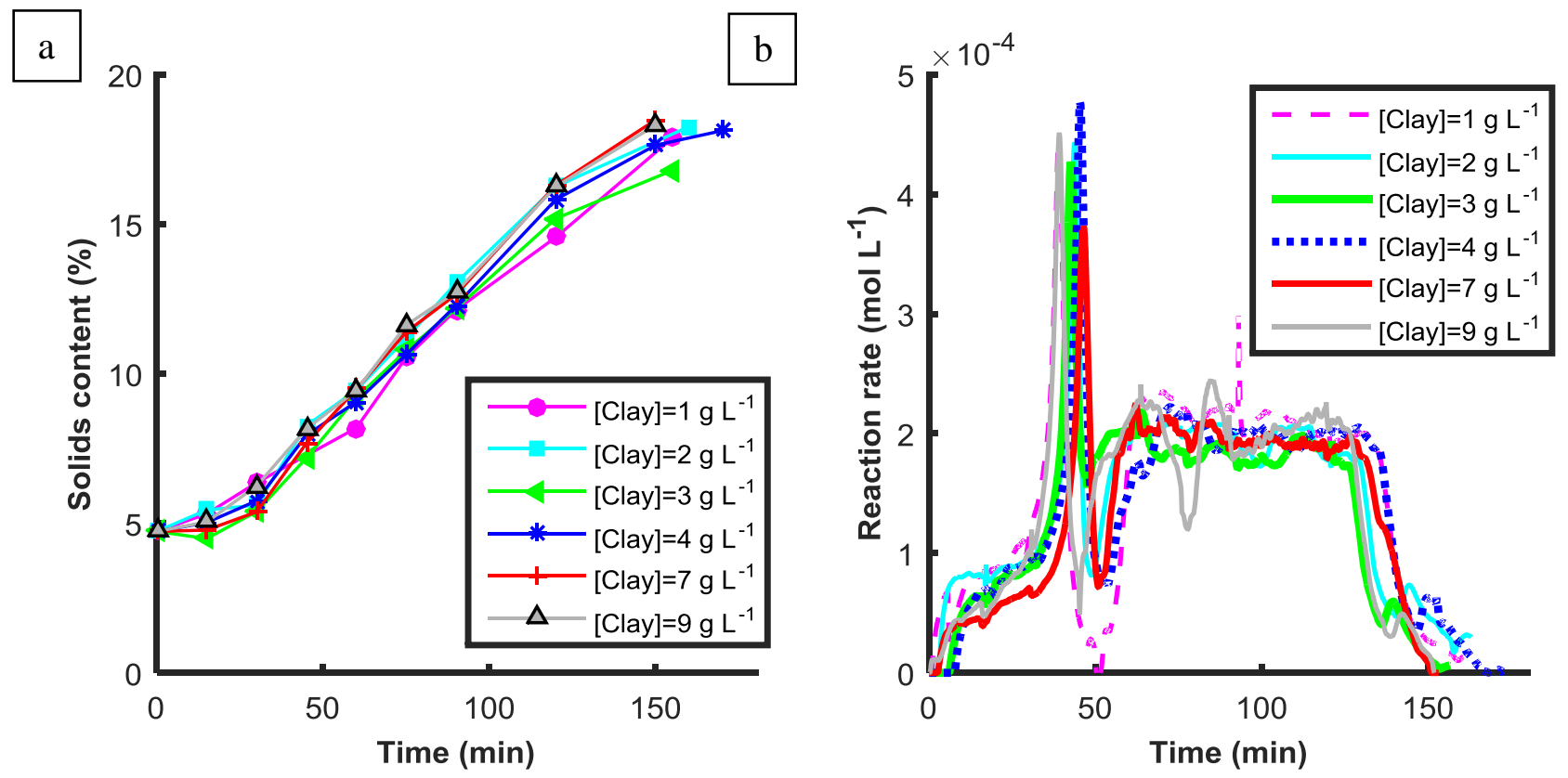

Figure 1: Pickering seeded semi-continuous emulsion polymerization of styrene stabilized with different amounts of Laponite RDS. (a) Solid content as a function of time, (b) Reaction rate.

\section{$A b$ initio experiments}

Surfactant-free emulsion polymerizations of styrene were carried out in the presence of clay particles dispersed in water at various concentrations. As described in the experimental section, polymer particles were produced in a first batch period; then in a second period, semi-continuous monomer addition was started. Based on offline measurements, a reaction period was selected for modeling where both of the following conditions were satisfied:

1) Particles were saturated with monomer (based on monomer and polymer concentrations)

2) The number of particles was constant with time (i.e. there was no secondary nucleation nor coagulation)

Only this period of the experiments was considered for modeling in order to investigate the effect of clay on radical capture while avoiding all effects on the reaction rate coming from other origins. 
The results of these $a b$ initio semi-continuous experiments are shown in Figures 2 and 3. Increasing clay concentration led to faster increase of the solids content and monomer conversion because of the higher reaction rates (Figure 2a and $b$ ). This can be attributed to a better stabilization of the nucleated particles and to a reduction in the coagulation rate during the first batch period. As a matter of fact, smaller particles were obtained for higher clay concentrations (Figure 2c), indicating that a greater number of particles has been nucleated (Figure 2d). The number of particles increased at the beginning of the reaction, during the nucleation period, and then stabilized until the end of the reaction. The nucleation period ended between 45 and 90 min and was longer for higher amounts of clay.

Figure 3a shows the measured PSD when the solids content was approximately $10 \%$. Very similar PSDs were observed for 5 and $10 \mathrm{~g} \mathrm{~L}^{-1}$, indicating no further effect of the clay concentration on the size distribution beyond this concentration range. The broad PSD observed for the lowest clay concentration $\left(0.1 \mathrm{~g} \mathrm{~L}^{-1}\right)$ indicates the occurrence of some coagulation events in this particular experiment (a slight decrease of the number of particles can also be observed in Figure 2d). Note that coagulation is neglected in the model presented above, which should be kept in mind when analyzing the results of this particular experiment. Figure $3 \mathrm{~b}$ shows the average number of radicals per particle calculated using the mean diameter (i.e. using the estimated reaction rate by calorimetry, and equation 3 for a mean particle size). Note that using an average diameter generates inaccuracies, mainly when the PSD is broad, which might lead to errors in $\bar{n}$. However, it can be seen that $\bar{n}$ is larger than one for most experiments, so that they cannot be modeled using the 0-1 model. The pseudo-bulk model was thus employed for modeling. 

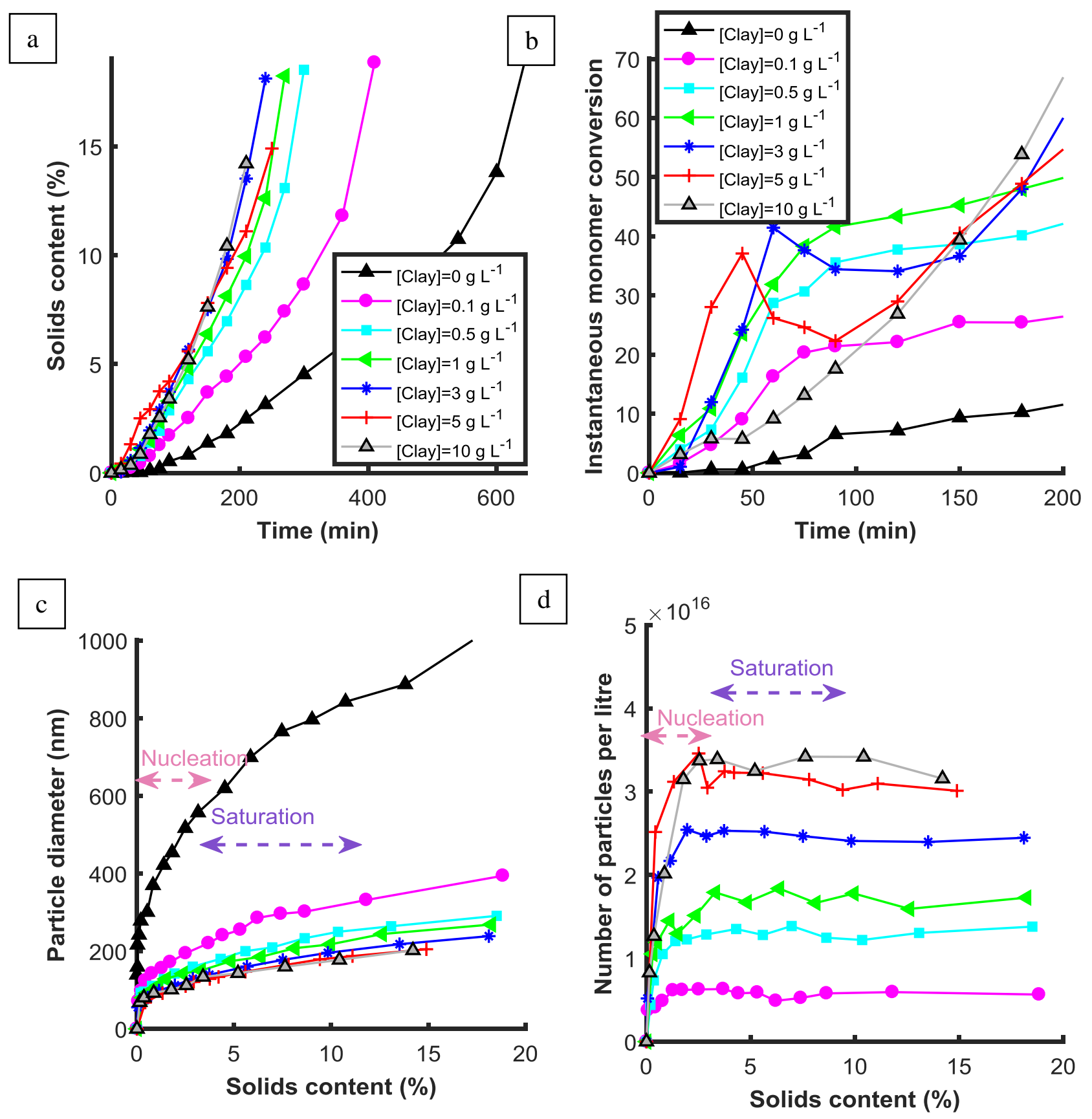

Figure 2: Pickering ab initio semi-continuous emulsion polymerization of styrene stabilized with different amounts of Laponite RDS. (a) Solids content as a function of time, (b) Monomer conversion as a function of time, (c) Particle diameter determined by DLS as a function of solids content, (d) Number of particles per liter. 

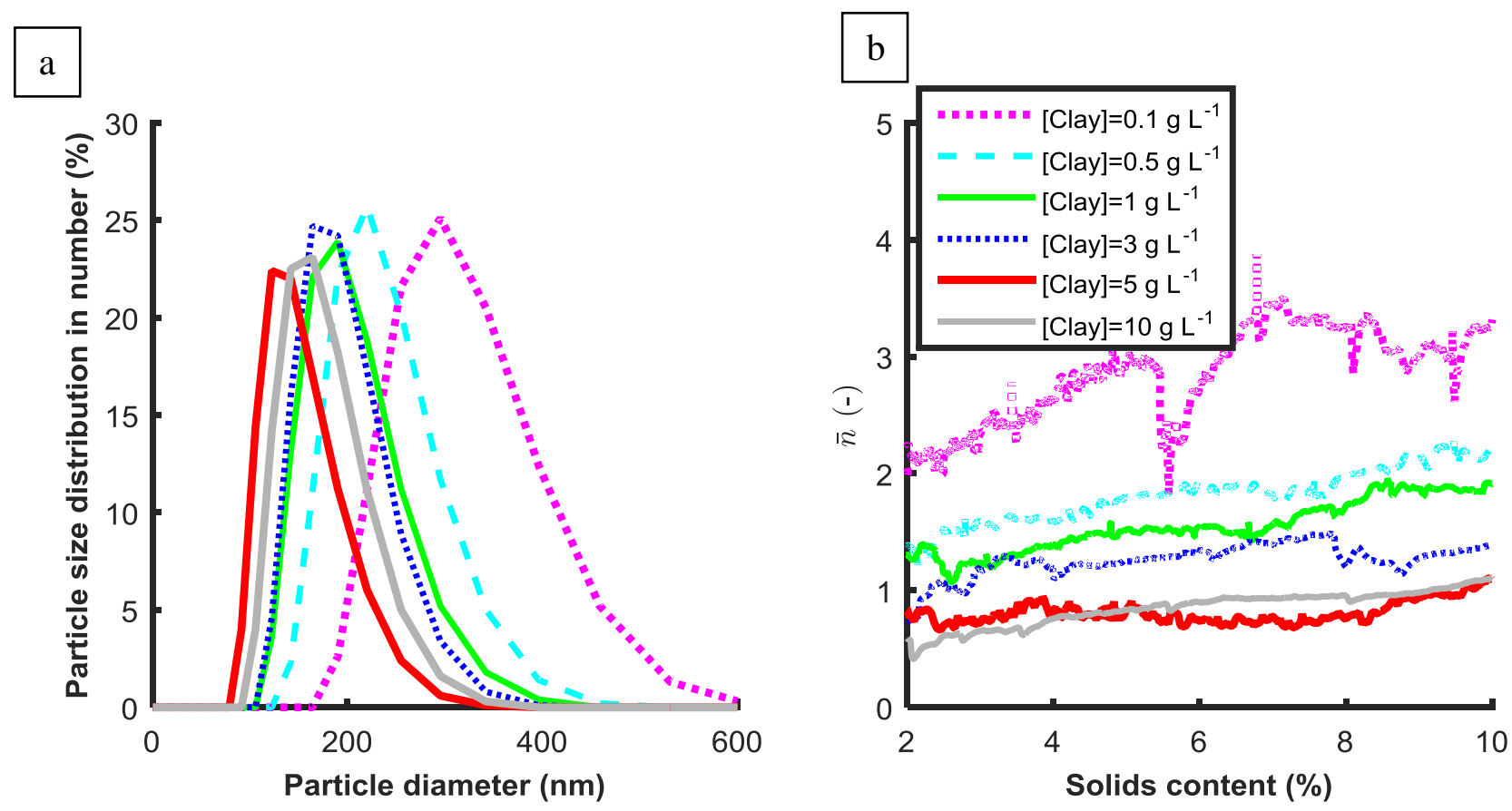

Figure 3: Pickering ab initio semi-continuous emulsion polymerization of styrene stabilized with different amounts of Laponite RDS. (a) Particle size distribution determined by DLS at SC $\approx$ $10 \%$. (b) Average number of radicals per particle, $\bar{n}$, as a function of solids content (calculated using a mean particle diameter).

Based on the different measurements, the period between 4 and $10 \%$ solids content was found to satisfy the two desired conditions regarding modeling: i) saturation of polymer particles by monomer, and ii) constant number of particles; this particular period was used in the subsequent sections. Note that the corresponding time periods differ between the experiments due to different reaction rates (only the clay concentration varies between the experiments).

The experimental results also indicate that the clay affects the number of particles and the reaction rate. The objective of modeling investigations considered in the following sections is to determine if the observed differences in these experiments are due to the fact that the presence of clay on the surface of polymer particles affects radical entry. If this is the case, then this effect should be taken into account in the radical entry model. Parameters for conventional emulsion polymerization of styrene were taken from the literature (Table 2). ${ }^{35,49,53}$ 
Table 2: Parameters used in the simulations (Styrene at $\mathbf{7 0}^{\circ} \mathrm{C}$ )

\begin{tabular}{lll}
\hline Parameter & Value & Reference \\
\hline$D_{p}\left(\mathrm{dm}^{2} \mathrm{~s}^{-1}\right)$ & $1.5 \times 10^{-7}$ & Sajjadi (2009) \\
$k_{d}\left(\mathrm{~s}^{-1}\right)$ & $2.2 \times 10^{-5}$ & Sajjadi (2009) \\
$k_{p}\left(\mathrm{dm}^{3} \mathrm{~mol}^{-1} \mathrm{~s}^{-1}\right)$ & 480 & Sajjadi (2009) \\
$k_{p_{w}}\left(\mathrm{dm}^{3} \mathrm{~mol}^{-1} \mathrm{~s}^{-1}\right)$ & 480 & Sajjadi (2009) \\
$k_{t_{w}}\left(\mathrm{dm}^{3} \mathrm{~mol}^{-1} \mathrm{~s}^{-1}\right)$ & $3 \times 10^{9}$ & Sajjadi (2009) \\
$k_{t_{p}}\left(\mathrm{dm}^{3} \mathrm{~mol}^{-1} \mathrm{~s}^{-1}\right)$ & $6.8 \times 10^{7}$ & Sajjadi (2009) \\
$k_{t r}\left(\mathrm{dm}^{3} \mathrm{~mol}^{-1} \mathrm{~s}^{-1}\right)$ & $9.3 \times 10^{-3}$ & Sajjadi (2009) \\
$m=[M]_{p}^{\text {sat }} /[M]_{w}^{s a t}$ & $1.0226 \times 10^{3}$ & Gilbert (1995) \\
{$[M]_{p}^{s a t}\left(\mathrm{~mol} \mathrm{~L}^{-1}\right)$} & 5.42 & Vanzo (1965) \\
{$[M]_{W}^{s a t}\left(\mathrm{~mol} \mathrm{~L}^{-1}\right)$} & $5.3 \times 10^{-3}$ & Vanzo (1965) \\
\hline
\end{tabular}

\section{Radical capture modeling in Pickering emulsion polymerization}

In this section, the $a b$ initio experiments will be used to choose an adapted model for radical capture. First, it is aimed to predict the radical capture dependency on the particle size, $d_{p}$. Then, the different models are used to estimate the effect of the clay concentration, either on the capture efficiency factor (in the diffusion model) or on the stability of entering radicals (in the colloidal model).

\section{$\underline{\text { Radical capture dependence on } d_{p} \text { and clay concentration }}$}

The methodology proposed by Asua and de la Cal (1991) was employed to determine the dependency on the particle size. ${ }^{54}$ In this methodology, the capture rate coefficient was assumed to have the following form:

$$
k_{e}=k_{e}^{*} d_{p}^{\alpha}
$$

where $k_{e}^{*}$ and $\alpha$ are adjustable parameters. Note that $\alpha=0$ in the propagation model, $\alpha=1$ in the diffusion and colloidal models, and $\alpha=2$ in the collision model. Also note that $\alpha$ has a direct influence on the broadening of the PSD with respect to time (assuming no coagulation, as the number of particles 
is constant in the considered period), while $k_{e}^{*}$ reveals the dependence of radical capture on the clay concentration (plus other parameters, e.g. temperature, solubility of radicals).

Thus, $\alpha$ was varied as follows $\alpha=0,1$ or 2 , and for each value of $\alpha$, the parameter $k_{e}^{*}$ was identified for each of the experiments separately, using the monomer conversion as minimization criterion. Figure 4 shows the identified values of $k_{e}^{*}$. Figure 5 shows the obtained conversion and PSD after fitting by the three possibilities of $\alpha$ in one of the experiments (with [Clay] $=10 \mathrm{~g} \mathrm{~L}^{-1}$ ).

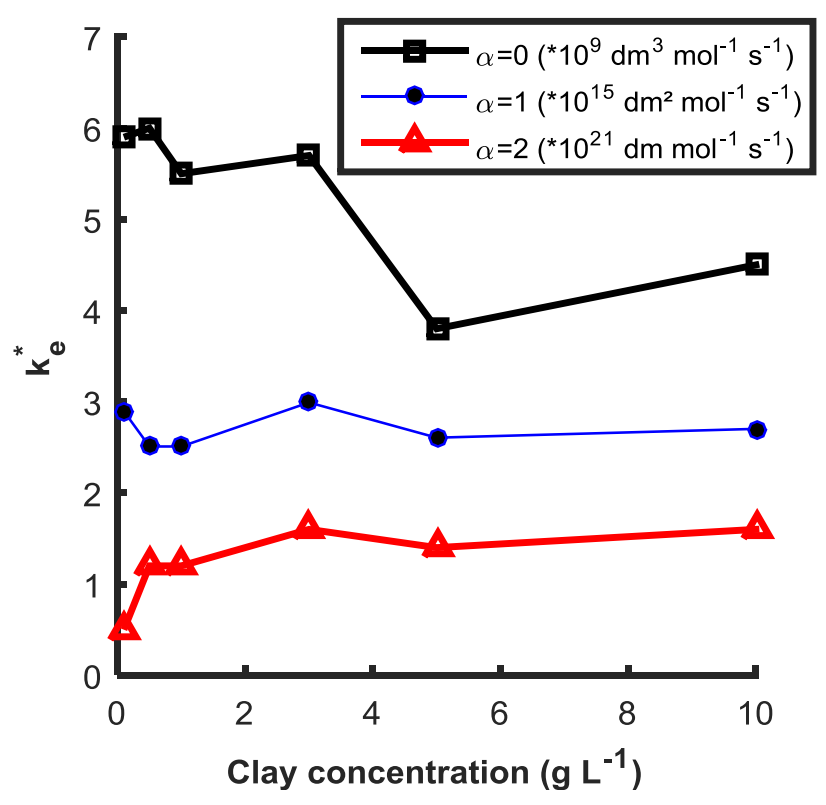

Figure 4: Identification of $k_{e}^{*}$ as a function of the clay concentration (for $\alpha=0,1$ or 2). 

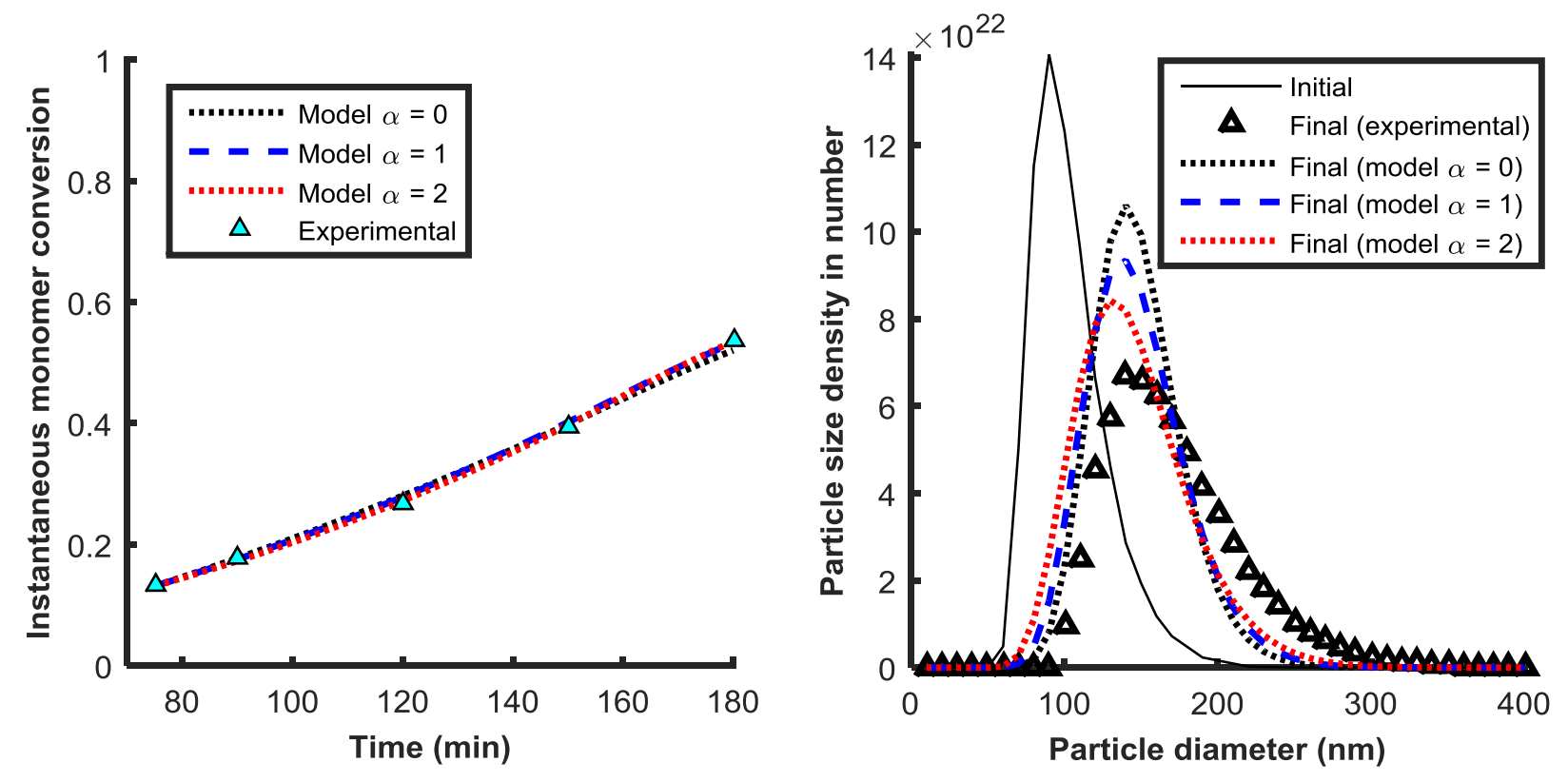

Figure 5: Monomer conversion and PSD in a Pickering emulsion polymerization using $10 \mathrm{~g} \mathrm{~L}^{-1}$ of clay and best fit of the models using the values of $k_{e}^{*}$ given in Figure 4 for $\alpha=0,1$ or 2 .

From these figures it appears that:

- $\boldsymbol{\alpha}=\mathbf{0}$ implied a decrease of the radical capture coefficient with the clay concentration. However, when investigating the PSD, it can be seen that this model did not allow to fit the broadening of the PSD occurring in this experiment, but the difference between the distributions remains quit low and does not allow to conclude. Among the available radical capture models in the literature, only the propagation model (equation 11) suggests $\alpha=0$ (no dependence on $d_{p}$ ). When this model was implemented, it under-predicted the reaction rate. Even when a capture efficiency was introduced into this model (i.e. $k_{\mathrm{e}}=f_{e} k_{\mathrm{p}}[\mathrm{M}]_{\mathrm{w}} \frac{N_{\mathrm{A}}}{N} \frac{\left[\mathrm{IM}_{\mathrm{z}-1}\right]_{\mathrm{w}}}{[\mathrm{R}]_{\mathrm{w}}}$ ), it was necessary to have $f_{e} \approx[6,10,14,20,8,15]$, when the clay concentration was varied as follows $[$ Clay $]=$ $[0.1,0.5,1,3,5,10] \mathrm{g} \mathrm{L}^{-1}$ respectively. Therefore, $f_{e}$ first increased slightly when increasing the clay concentration then oscillated. This indicates no hindrance of radical capture by the clay layer. Moreover, such values are not realistic, as efficiency factors should be lower than one. It is 
worthy to remind that the polymerization temperature in the present study was $70^{\circ} \mathrm{C}$ while it was $50^{\circ} \mathrm{C}$ in Maxwell and Gilbert experiments, ${ }^{47}$ which might be the reason why this admitted radical capture mechanism does not fit our experimental results.

- $\boldsymbol{\alpha}=\mathbf{1}$ showed no dependence of $k_{e}^{*}$ on the clay concentration, and gave acceptable results in terms of PSD predictions. In the literature, two radical capture models assume $\alpha=1$, the diffusion and colloidal models, that will hence be considered in the following sections in order to identify $f_{e}$ or $W$, respectively.

- $\quad \boldsymbol{\alpha}=\mathbf{2}$ implied a slight increase in $k_{e}^{*}$ when increasing clay concentration mainly for low clay concentrations (up to $5 \mathrm{~g} \mathrm{~L}^{-1}$ ). This is counter-intuitive as the clay and the KPS radicals do not experience attractive interactions. In terms of PSD broadening, this model led to the best estimate. A similar observation was found by Liotta et al. (1997) who indicated that the particle size for polystyrene in their experimental data suggested a dependence of $k_{e}$ on $d_{p}^{1.85} \cdot{ }^{55}$ Among the radical capture models, only the collision model (equation 8) suggests $\alpha=2$ (dependence on $d_{p}^{2}$ ). However this model is valid only for interval I, when the polymer particles are small. This model was though used to identify the degree of polymerization before precipitation in our experiments in interval II. The obtained values were as follows $j_{c r} \approx$ $[0.05,0.3,0.3,0.5,0.8,0.5]$, when the clay concentration was $[$ Clay $]=[0.1,0.5,1,3,5,10] \mathrm{g} \mathrm{L}^{-}$ ${ }^{1}$ respectively. These values are aberrant as the degree of precipitation should at least be equal to one, and the precipitation degree for styrene is known to be $j_{c r}=5$. Note that this model does not include a radical capture efficiency factor, which could be suggested to widen its applicability; it would however become a supplementary empirical parameter to be fitted to experiments. 


\section{Capture efficiency, $f_{e}$, in the diffusion model}

Identification of $f_{e}$ in the diffusion model (i.e. $\alpha=1$ ) was done using equation 7. Figure 6 shows the obtained values for the different clay concentrations. First, no effect of the clay concentration can be detected here. Moreover, $f_{e}$ is much lower than one in all experiments, which means that the model of Smith and Ewart is not satisfactory. Similar values of the capture rate efficiency coefficient were obtained for conventional emulsion polymerization of styrene at $70{ }^{\circ} \mathrm{C}$ using sodium dodecyl sulfate as surfactant $\left(k_{e}^{*}=1.4 \times 10^{21} \mathrm{~L} \mathrm{~mol}^{-1} \mathrm{~s}^{-1}\right) .{ }^{56}$ Therefore, it can be concluded that the presence of clay does not lead to a reduction in $f_{e}$.

The mean value of the capture efficiency around $f_{e}=1.4 \%$ gives $k_{e}=8.1 \times 10^{9} \mathrm{dm}^{3} \mathrm{~mol} \mathrm{~s}^{-1}$ for particles of diameter $300 \mathrm{~nm}$. Using this mean value, good fits of the model to all the experiments could be achieved. The resulting estimates of the average number of radicals per particle, $\bar{n}$, are shown in Figure 7 for different clay concentrations. $\bar{n}$ increases with respect to decreasing the clay concentration and with respect to increasing the solids content. Both variations are due to the increase of the particles size with time, and not to the presence of clay. 


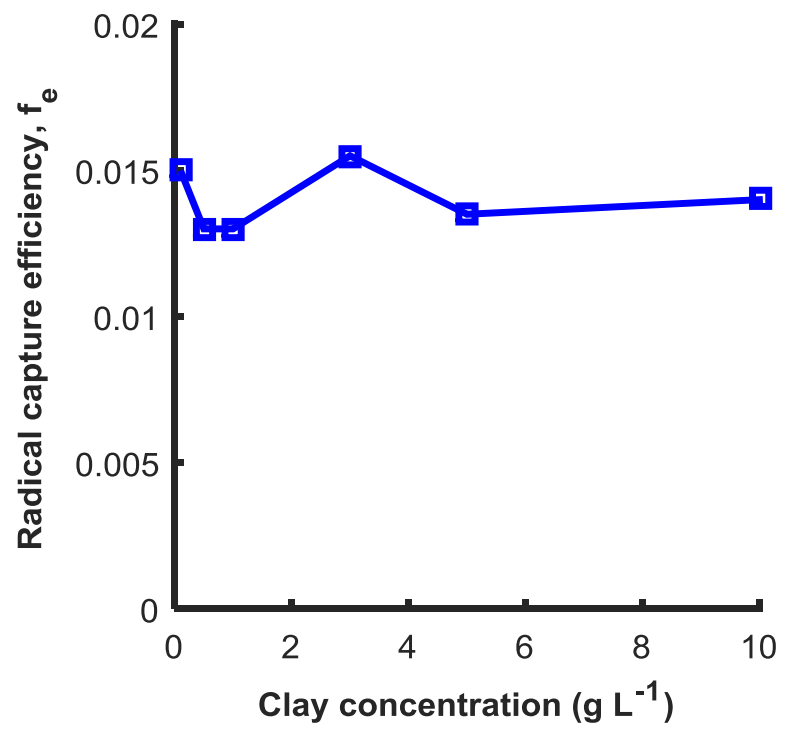

Figure 6: Identification of the radical capture efficiency $f_{e}$ in the diffusion model $(\alpha=1)$.

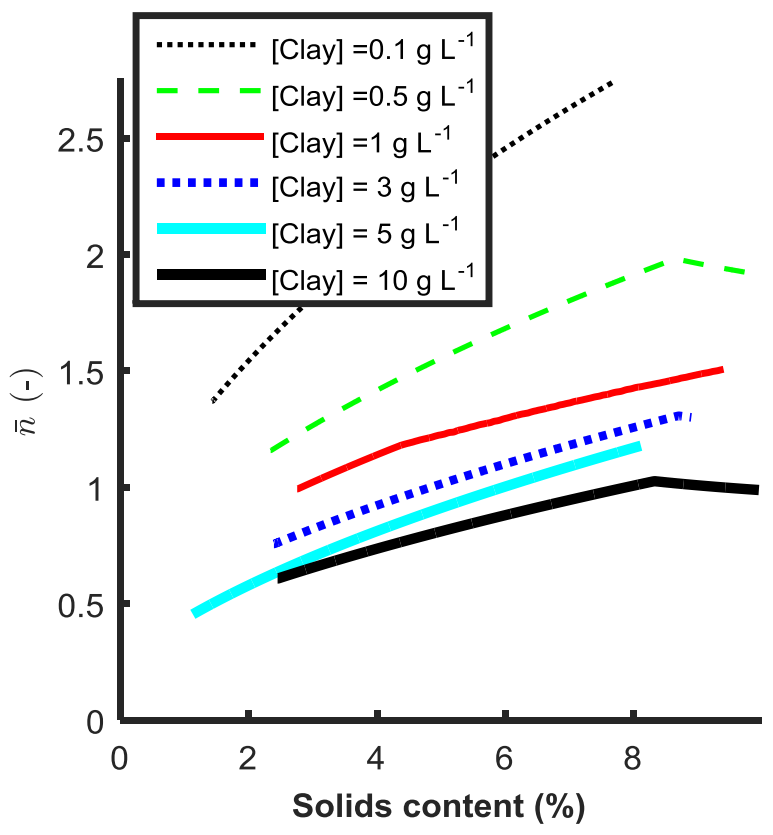

Figure 7: Estimation of $\bar{n}$ using the average value of $f_{e}=1.4 \%$ using the diffusion model $(\alpha=1)$ 

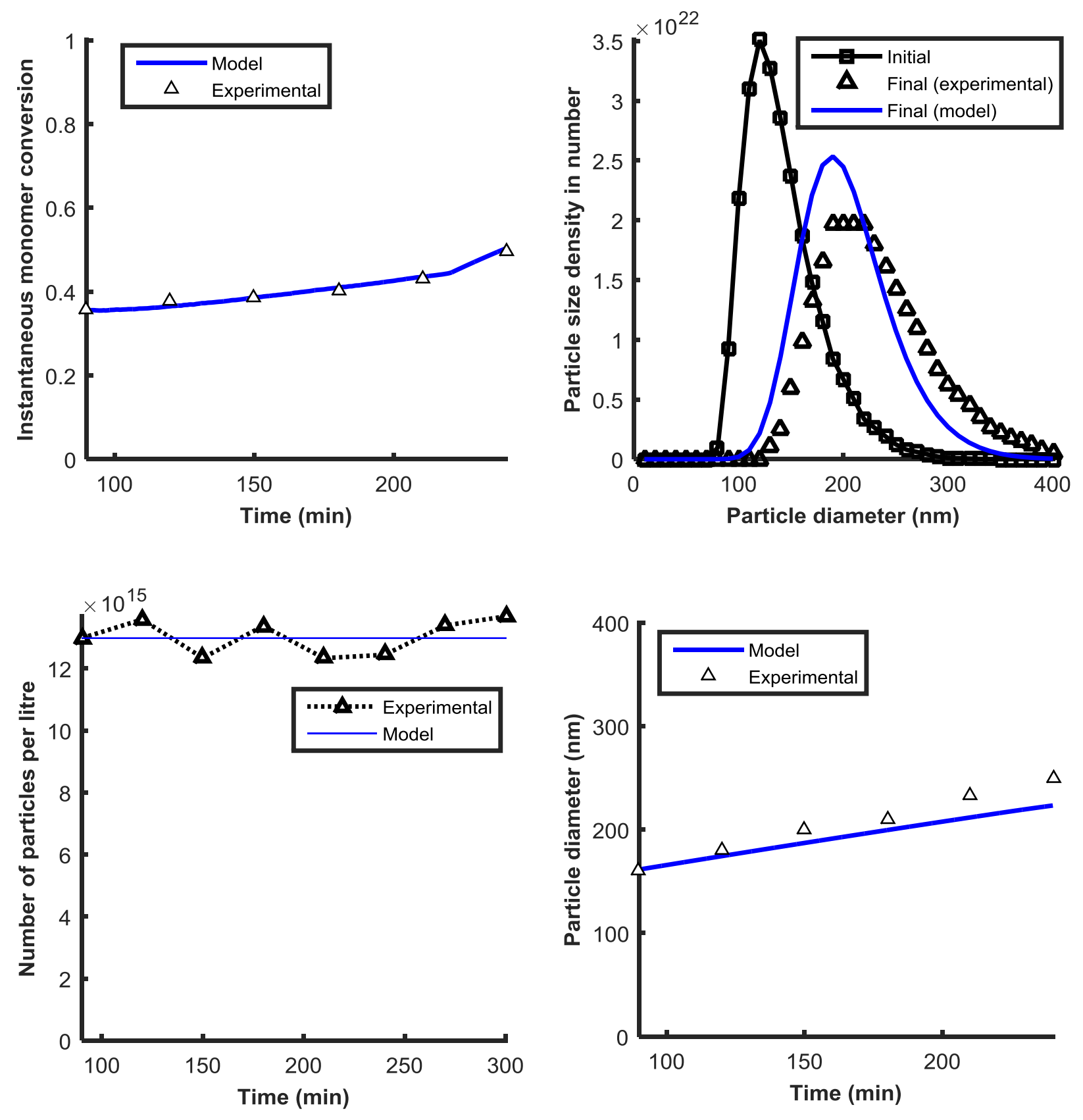

Figure 8: Pickering emulsion polymerization involving $0.5 \mathrm{~g} \mathrm{~L}^{-1}$ of clay (diffusion model, $f_{e}=$ $1.4 \%)$.

The detailed experiment shown in Figure 8 corresponds to a clay concentration of $0.5 \mathrm{~g} \mathrm{~L}^{-1}$. The diffusion model fitted very well to the kinetics of monomer conversion, but a small discrepancy can be 
observed regarding the PSD as well as the mean diameter. This might be due to different reasons: first of all, coagulation might have not been totally eliminated, even though the calculated number of particles was constant during all the experiments. The modeling errors may also arise from an error in the different coefficients, as some of them are not known at $70{ }^{\circ} \mathrm{C}$ (e.g. concentration of monomer under saturation). There might be also some measurement errors due to the dilution of the latex in water required to measure the PSD, which might lead to escaping part of the monomer from the polymer particles.

\section{Stability of entering radicals, $W$, in the colloidal model}

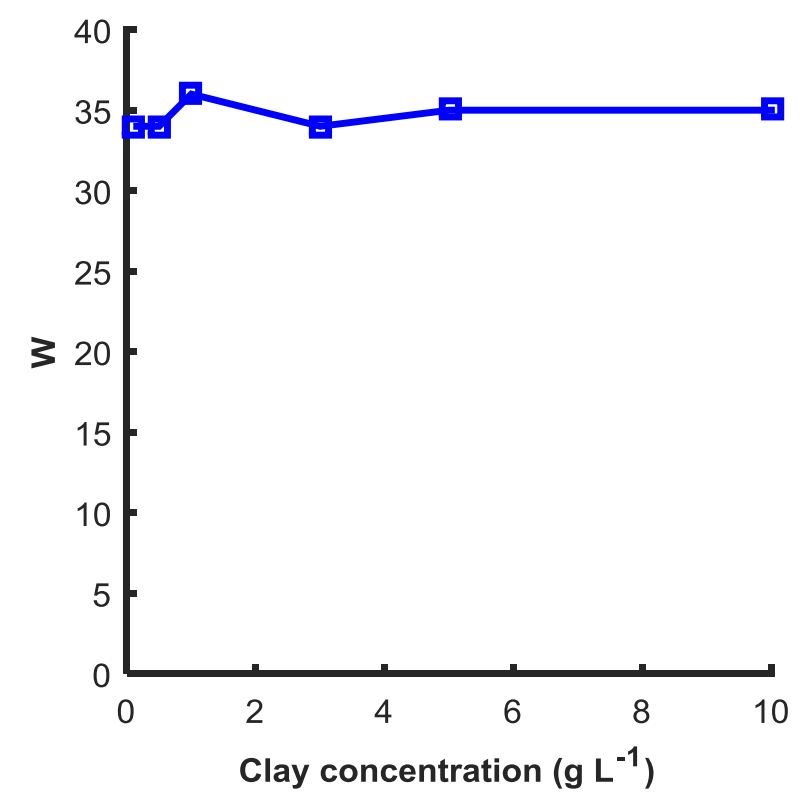

Figure 9: Identification of $W$ in the colloidal model (Penboss et al. 1986) $(\alpha \approx 1)$.

The stability of the entering radicals was estimated using the colloidal model $(\alpha \approx 1)$ (equation 9).

Figure 9 shows that an average value of $W=35$ is obtained from the experiments with the different clay concentrations, indicating that the clay concentration does not influence radical capture. Note that a higher stability of radicals is equivalent to a lower efficiency factor of radical capture, as stable radicals are supposed not to aggregate on polymer particles. Figure 10 shows the results obtained with $W=35$, 
for the experiment with clay concentration $1 \mathrm{~g} \mathrm{~L}^{-1}$. The shape of the PSD is equivalent to that obtained with the diffusion-controlled model, with $f_{e}=1.4 \%$ (as both models are proportional to the particle size). Therefore, both of these models can be used to model the present system, independently of the clay concentration.
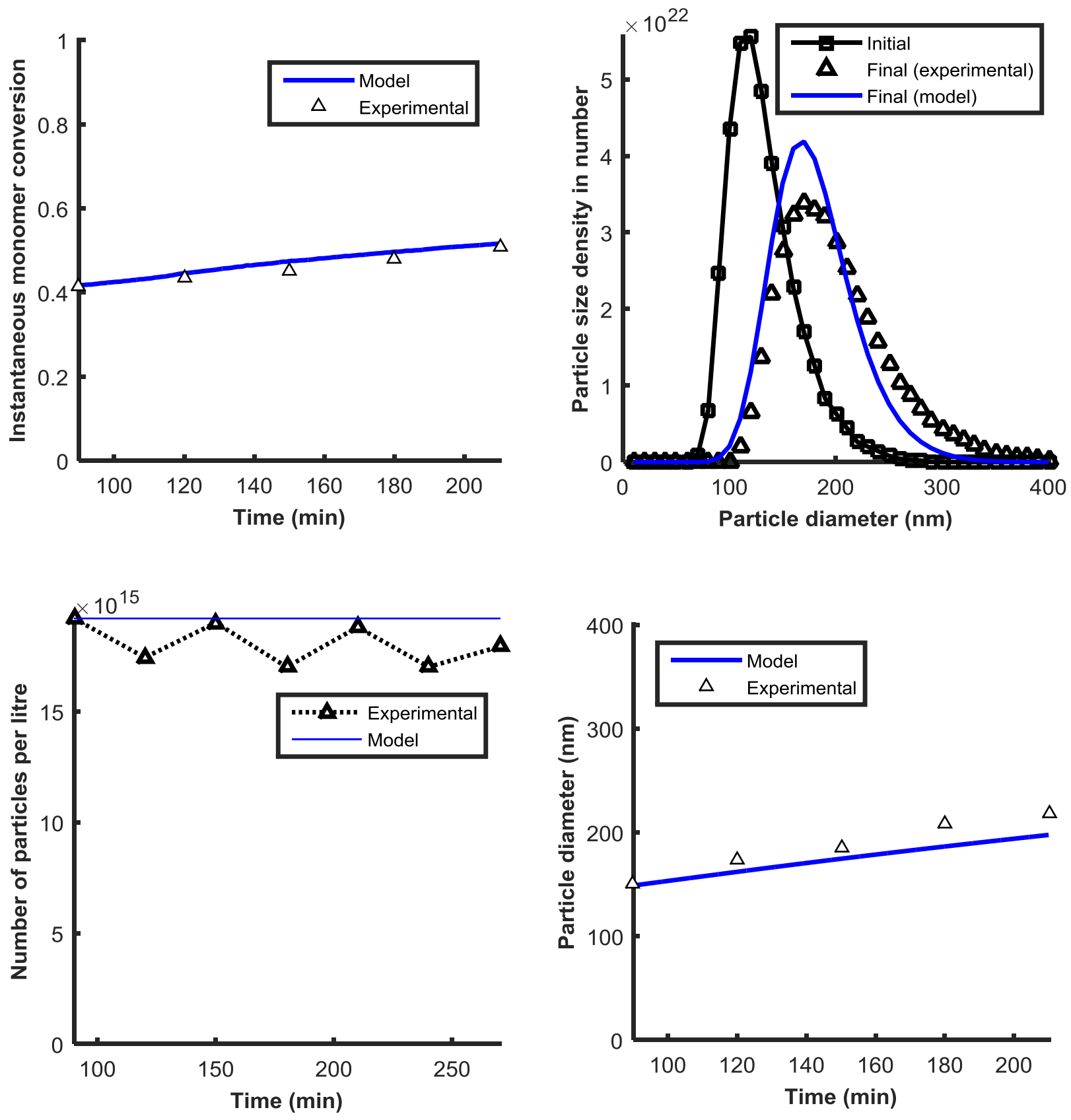

Figure 10: Pickering emulsion polymerization involving $1 \mathrm{~g} \mathrm{~L}^{-1}$ of clay (colloidal model, $W=35$ ). 


\section{Conclusions}

Pickering emulsion polymerization of styrene was considered in the presence of clay platelets to ensure particle stabilization. Seeded experiments, where the particle size and number were identical, did not show any dependency of the reaction rate on the clay concentration. Extrapolation of this hypothesis to ab initio experiments was then considered, which required the use of advanced modeling in order to account for the variation of the particle size and number when the clay concentration was varied. The period when polymer particles were saturated with monomer was considered for modeling. In the selected period, the number of particles was constant as well as the concentration of monomer in the polymer particles. It was observed that the particle diameter decreased with increasing the clay concentration up to $5 \mathrm{~g} \mathrm{~L}^{-1}$, due to an enhanced stability of the particles during the batch period. Above this limit, the clay concentration did not seem to affect the reaction rate or particle size.

Investigation of the available radical capture models also showed that the diffusional $(\alpha=1)$ or colloidal $(\alpha \approx 1)$ models might fit to the experiments if the radical capture efficiency $f_{e}$ or oligoradical stability ratio $W$ were adjusted, respectively. The mean radical capture efficiency of all the present experiments was evaluated as $f_{e}=1.4 \%$ and the mean stability of entering radicals as $W=35$.

The propagation model (that is independent of the particle size, $\alpha=0$ ) was not adapted to the present system for two reasons. It could not fit the broadening of the particle size distribution observed in these experiments, however the bias at estimating the PSD width by DLS measurements makes this argument weak. The main reason is that this model underestimated the radical capture rate.

The collision model $(\alpha=2)$ led to identified degrees of polymerization lower than one when fitted to our experiments. Moreover, the results of this model indicated an increase of the radical capture rate when increasing the clay concentration mainly for low clay concentrations which is counter-intuitive. It 
is important to remind however that this model was initialy proposed for interval I (i.e. small particles). An efficiency factor might be added to this model to make it fit to the experiments as well as to thermodynamic considerations.

Precise process modeling predicted that the average number of radicals per particle decreased with increasing the clay concentration. This was found to be due only to the decrease in the particle size and not to limitations in radical capture. Thus, as an answer to the starting question, the classical capture models proposed in the framework of emulsion polymerization in the presence of surfactant stabilizers can fit to the several experimental measurements for Pickering emulsion polymerization using Laponite clay platelets. The estimated radical capture coefficient is similar to that obtained using conventional surfactant indicating no hindrance of radical capture resulting from the presence of clay at the particle surface. $^{56}$

The present results might be in contradiction with the intuitive idea that clay particles could obstruct part of the polymer particles surface, thereby leaving a lower area available for radical entry. A more microscopic modeling describing the underlying physicochemical processes may be considered to explain this observation. It might be hypothesized however that the main barrier against radical entry is long-range electrostatic repulsion between negatively charged oligoradicals and particle surface. As the surface charge density of polymer particles is essentially that of clay platelets, whatever the coverage, electrostatic repulsions may be independent of the coverage by clay. A clue to such hypothesis is that neither the efficiency factor $f_{\mathrm{e}}$ in the diffusion-controlled radical capture model nor the stability ratio $W$ in the colloidal model depend on the clay concentration.

\section{Nomenclature}

c pseudo-first order termination rate coefficient between two chains $\left(\mathrm{s}^{-1}\right)$ 
$f \quad$ initiator efficiency

$f_{e} \quad$ efficiency of radical entry

$f_{M} \quad$ frequency at which monomeric radicals are formed

[I] concentration of initiator $\left(\mathrm{mol} \mathrm{L}^{-1}\right)$

$\left[I M_{i}^{\bullet}\right]_{w}$ concentration of monomeric radicals of length $i$ in the water phase $\left(\mathrm{mol} \mathrm{L}^{-1}\right)$

$d_{p} \quad$ particle diameter $(\mathrm{dm})$

$d_{i} \quad$ diameter of radical of length $i(\mathrm{dm})$

$D_{w} \quad$ monomer diffusion coefficient in water $\left(\mathrm{dm}^{2} \mathrm{~s}^{-1}\right)$

$D_{w(i)} \quad$ diffusion rate coefficient of radical of length $i$ in water $\left(\mathrm{dm}^{2} \mathrm{~s}^{-1}\right)$

$D_{p} \quad$ average diffusion rate coefficient of monomeric radicals in the polymer particles $\left(\mathrm{dm}^{2} \mathrm{~s}^{-1}\right)$

$E_{\text {des }} \quad$ activation energy of desorption (J)

$F(r, t)$ number density of particles (part $\left.\mathrm{L}^{-1}\right)$

$f_{d} \quad$ frequency of monomeric radicals formation $\left(\mathrm{s}^{-1}\right)$

$f_{e} \quad$ radical capture efficiency term (-)

$F_{m} \quad$ inlet monomer flow rate $\left(\mathrm{mol} \mathrm{s}^{-1}\right)$

$G(r, t)$ growth rate of particles of radius $r\left(\mathrm{dm} \mathrm{s}^{-1}\right)$

$j_{c r} \quad$ critical degree of polymerization (-)

$k_{0} \quad$ equilibrium radical desorption coefficient $\left(\mathrm{dm}^{3} \mathrm{~mol}^{-1} \mathrm{~s}^{-1}\right)$

$k_{B} \quad$ Boltzmann constant $\left(\mathrm{m}^{2} \mathrm{~kg} \mathrm{~s}^{-2} \mathrm{~K}^{-1}\right)$

$k_{d} \quad$ initiator decomposition coefficient $\left(\mathrm{s}^{-1}\right)$

$k_{\text {des }} \quad$ radical desorption rate coefficient $\left(\mathrm{s}^{-1}\right)$

$k_{e} \quad$ radical capture rate coefficient $\left(\mathrm{dm}^{3} \mathrm{~mol}^{-1} \mathrm{~s}^{-1}\right)$ 
$k_{p} \quad$ propagation rate coefficient (in water and in particles) $\left(\mathrm{dm}^{3} \mathrm{~mol}^{-1} \mathrm{~s}^{-1}\right)$

$k_{t_{p}} \quad$ termination rate coefficient in the polymer particles $\left(\mathrm{dm}^{3} \mathrm{~mol}^{-1} \mathrm{~s}^{-1}\right)$

$k_{t_{w}} \quad$ termination rate coefficient in the aqueous phase $\left(\mathrm{dm}^{3} \mathrm{~mol}^{-1} \mathrm{~s}^{-1}\right)$

$k_{f M} \quad$ transfer to monomer rate coefficient in the polymer particles $\left(\mathrm{dm}^{3} \mathrm{~mol}^{-1} \mathrm{~s}^{-1}\right)$

$L \quad$ distance travelled by the entering radical (dm)

$m \quad$ partition coefficient of radicals between the polymer particles and water (-)

$M_{W} \quad$ monomer molecular weight $\left(\mathrm{kg} \mathrm{mol}^{-1}\right)$

$[M]_{p} \quad$ monomer concentration in the polymer particles $\left(\mathrm{mol} \mathrm{dm}{ }^{3}\right)$

$[M]_{p}^{\text {sat }}$ saturation monomer concentration in the polymer particles $\left(\mathrm{mol} \mathrm{dm}{ }^{3}\right)$

$[M]_{w} \quad$ monomer concentration in the aqueous phase $\left(\mathrm{mol} \mathrm{dm}{ }^{3}\right)$

$[M]_{w}^{s a t}$ saturation monomer concentration in the aqueous phase $\left(\mathrm{mol} \mathrm{dm}{ }^{3}\right)$

$N \quad$ number of monomer-swollen polymer particles per unit volume of latex (part $\mathrm{L}^{-1}$ )

$\bar{n}(r, t)$ average number of radicals per particles of size $r(-)$

$N_{A} \quad$ Avogadro's number $\left(\mathrm{mol}^{-1}\right)$

$N_{m} \quad$ Number of moles of residual monomer (mol)

$P \quad$ probability of the radical to escape the particle before undergoing other reactions (-)

$P_{p} \quad$ probability of radical reaction inside the particles (-)

$P_{w} \quad$ probability of radical reaction in the aqueous phase (-)

$r \quad$ particle radius $(\mathrm{dm})$

$R \quad$ rate of radical generation $\left(\mathrm{mol} \mathrm{s}^{-1} \mathrm{~L}^{-1}\right)$

$R_{p_{p}} \quad$ polymerization rate inside the particles $\left(\mathrm{mol} \mathrm{s}^{-1} \mathrm{~L}^{-1}\right)$

$[R]_{w}$ total concentration of radicals in the aqueous phase $\left(\mathrm{mol} \mathrm{L}^{-1}\right)$ 


$\begin{array}{ll}T & \text { reaction temperature (K) } \\ t_{\text {prec }} & \text { the radical precipitation time (s) } \\ V & \text { volume of the reaction medium (L) } \\ v_{s} & \text { volume of swollen polymer particles (L) } \\ W & \text { stability ratio (-) } \\ z & \text { radical critical length for entry (-) } \\ z_{\alpha} & \text { zeta potential } \\ \rho & \left.\text { rate of radical entry ( } \mathrm{s}^{-1}\right) \\ \rho_{m} & \text { monomer density }\left(\mathrm{kg} \mathrm{L}^{-1}\right) \\ \rho_{p} & \left.\text { polymer density (kg } \mathrm{L}^{-1}\right) \\ \alpha & \text { fitting parameters of the radical entry model (-) } \\ \eta & \text { viscosity of the medium (Pa s) }\end{array}$

\section{Appendix: Modeling}

\section{Aqueous phase reactions}

Aqueous phase reactions and models of Pickering emulsion polymerization are the same as those of conventional emulsion polymerization. Different reaction schemes can be considered, thus leading to different mass balances. The main hypothesis considered in this work are given in detail in a previous paper, dedicated to the modeling of emulsion polymerization of styrene using the same persulfate initiator. ${ }^{56}$ The main assumptions to be outlined here are the following: $i$ ) oligomeric species may attain a maximal length of $i=j_{c r}$ monomer units in the aqueous phase, beyond which either radical capture or precipitation takes place; ii) radical transfer to monomer in the aqueous phase is negligible due to the 
low low solubility of styrene in water; iii) radical capture into polymer particles concerns only aqueous phase radicals of sizes $z<i<j_{c r}$, with $z=3$ and $j_{c r}=5$ for styrene; ${ }^{49}$ and $i v$ ) no differentiation is done between the radical groups originating from initiator decomposition or those produced by transfer to monomer inside the polymer particles, i.e. desorbed monomeric radicals are considered as $\left[I M_{1}^{\bullet}\right]_{w}$. According to these assumptions, the following material balances are obtained for aqueous phase radicals after applying the quasi-steady state assumption for the total concentration of radical species:

$$
\begin{gathered}
{\left[I M_{1}^{\bullet}\right]_{w}=\frac{2 f k_{d}[I]+\frac{1}{N_{A}} \int_{0}^{\infty} k_{d e s} \bar{n}(r, t) F(r, t) d r}{k_{p}[M]_{w}+k_{t_{w}}[R]_{w}}} \\
{\left[I M_{3}^{\bullet}\right]_{w}=\frac{k_{p}[M]_{w}\left[I M_{1}^{\bullet}\right]_{w}}{k_{p}[M]_{w}+k_{t_{w}}[R]_{w}+\frac{1}{N_{A}} \int_{0}^{\infty} k_{e} F(r, t) d r}} \\
{\left[I M_{4}^{\bullet}\right]_{w}=\frac{k_{p}[M]_{w}+k_{t_{w}}[R]_{w}}{k_{p}\left[M M_{w}\left[I M M_{3}^{\bullet}\right]_{w}\right.}}
\end{gathered}
$$

The total concentration of radicals in the aqueous phase is given by:

$$
[R]_{w}=\sum_{i=1}^{j_{c r}-1}\left[I M_{i}^{\bullet}\right]_{w}
$$

\section{Monomer balance}

The monomer balance is given by: 


$$
\frac{d N_{m}}{d t}=F_{m}-\underbrace{k_{p}[M]_{p} \bar{n} N / N_{A}}_{R_{p_{p}}} V
$$

The reaction in the aqueous phase is considered to be negligible.

In the considered reaction period for modeling, polymer particles were assumed saturated with monomer all the time. Equilibrium is assumed fast enough to ensure reacted monomer within the polymer particles to be instantaneously replaced by monomer from droplets, and the saturation value is considered size independent. This assumption was experimentally validated for the present system based on a preliminary set of experiments where the stirring rate was varied between 350 and $600 \mathrm{rpm}$. It was observed that the stirring speed of $400 \mathrm{rpm}$ (with the considered 3-blade impeller) does not induce any mass transfer limitation (as similar reaction rates and properties were obtained as with 500 rpm). Some shear-induced coagulation was observed at $600 \mathrm{rpm}$ (increase in the particle size compared to the other stirring rates). $[M]_{w}$ and $[M]_{p}$ are thus maintained at their saturation values which are known. This allows all the coefficients to be considered constant with time, such as the propagation, termination and radical diffusion coefficients.

\section{Radical desorption models}

For many important emulsion polymerization systems, desorption represents the major cause of the loss of free-radical activity inside a particle as it decreases the concentration of radicals in the particles. As mentioned in the introduction, desorption mainly concerns monomeric radicals, derived from the transfer reactions to the monomer. Therefore, it may safely be assumed that desorption of monomer radicals would not be affected by the surfactant layer due to their small size (few monomer units) and to the fact that they are not charged (as the monomer is nonionic and monomeric radicals do not contain an initiator fragment). 
The desorption rate is given by the following equation:

$$
R_{\text {des }}=k_{\text {des }} \bar{n}
$$

where the desorption rate coefficient, $k_{\text {des }}$, is supposed to reflect all necessary conditions for desorption. Different precision levels were considered in the desorption models which gained in complexity with time, going from simple diffusion (Smith and Ewart $(1948)^{31}$, Ugelstad et al. $(1969)^{39}$, Chang et al. (1981) ${ }^{57}$, Morrison et al. $\left.(1994)^{58}\right)$, to models taking into account competitive reactions inside the particles (e.g. Harada et al. $(1971)^{52}$ ), and finally accounting for competitive radicals in the aqueous phase or fate of exited radicals (Asua et al. $1989^{59}$, Hernandez and Tauer $(2008)^{51}$, Ghielmi et al. $\left.(2014)^{60}\right)$. This last mechanism is the one admitted nowadays. In this mechanism, a radical is considered to be effectively desorbed from the particle only after it reacts in the aqueous phase. Desorbed radicals that are reabsorbed by a polymer particle before undergoing any reactions in the aqueous phase are not included in the desorption term. In this mechanism, the desorption rate coefficient takes the following form:

$$
k_{d e s}=f_{M} * P
$$

where $f_{M}$ is the frequency at which monomeric radicals (that may exit) are being formed, which mainly concerns transfer to monomer reactions (as well as to chain transfer agents, if present):

$$
f_{M}=k_{f M}[M]_{p}
$$

$P$ is the probability of the radical to escape the particle before undergoing other reactions (propagation and termination) inside the particle and to undergo reactions in the aqueous phase (Hernandez and Tauer $\left.2008^{51}\right)$ :

$$
P=\frac{P_{\mathrm{w}}\left(1-P_{\mathrm{p}}\right)}{1-\left(1-P_{\mathrm{w}}\right)\left(1-P_{\mathrm{p}}\right)}
$$

where the probability of radical reaction inside the particles is given by: 


$$
P_{\mathrm{p}}=\frac{\sum_{i} k_{i, \mathrm{p}}}{k_{0}+\sum_{i} k_{i, \mathrm{p}}}
$$

and the probability of radical reaction in the aqueous phase is:

$$
P_{\mathrm{w}}=\frac{\sum_{i} k_{\mathrm{i}, \mathrm{w}}}{\frac{k_{\mathrm{e}} N}{N_{\mathrm{A}}}+\sum_{i} k_{\mathrm{i}, \mathrm{w}}}
$$

where $k_{i, \mathrm{p}}$ and $k_{i, \mathrm{w}}$ are rate coefficients for the $i^{\text {th }}$ competitive reaction in the polymer and aqueous phase, respectively, e.g. $\sum_{i} k_{i, \mathrm{w}}=k_{\mathrm{pw}}[\mathrm{M}]_{\mathrm{w}}+k_{\mathrm{tw}}[R]_{w} . k_{e}$ is the radical capture rate coefficient and $k_{0}$ is the equilibrium radical desorption rate coefficient given for instance by (Harada et al. 1971): ${ }^{52}$

$$
k_{0}=\frac{12 D_{\mathrm{p}} D_{\mathrm{w}}}{d^{2}\left(m D_{\mathrm{p}}+D_{\mathrm{w}}\right)}
$$

where $m$ is the partition coefficient of the radicals between the polymer particles and the aqueous phase, $m=\left[I M_{i}^{\bullet}\right]_{p} /\left[I M_{i}^{\bullet}\right]_{w}$ usualy approximated by $[M]_{p} /[M]_{w}$ (or assumed as a tuning parameter). Another way of calculating $k_{0}$ was proposed by Brooks and Makanjuola $(1981)^{61}$ as well as Hernandez and

Tauer $(2008)^{51}$ based on the energy barrier for desorption due to the difference in chemical potential of the radicals between the phases as well as the presence of surfactant layers around the particles.

\section{Acknowledgement}

The support of the Agence Nationale pour la Recherche is gratefully acknowledged (PickEP project, grant $n^{\circ}$ ANR-12-JS09-0007-01). 


\section{References}

1. Bourgeat-Lami E, Lansalot M. Organic/Inorganic composite latexes: The marriage of emulsion polymerization and inorganic chemistry. In Hybrid Latex Particles; van Herk, A. M., Landfester, K., Eds.; Adv. Polym. Sci.; Springer Berlin Heidelberg, 2010:53-123.

2. Bourgeat-Lami E, Sheibat-Othman N, Dos Santos AM. Polymer-clay nanocomposite particles and soap-free latexes stabilized by clay platelets: State of the art and recent advances. In Polymer Nanocomposites by Emulsion and Suspension; Mittal, V., Ed.; RSC Publishing, 2010:269-311.

3. Sheibat-Othman N, Cenacchi-Pereira AM, Santos AMD, Bourgeat-Lami E. A kinetic investigation of surfactant-free emulsion polymerization of styrene using laponite clay platelets as stabilizers. J. Polym. Sci. A Polym. Chem. 2011:49:4771-4784.

4. Ruggerone R, Plummer CJ, Herrera NN, Bourgeat-Lami E, Manson JAE. Mechanical properties of highly filled latex-based polystyrene/laponite nanocomposites. Solid State Phenomena. 2009:151:30-34.

5. Herrera NN, Letoffé JM, Putaux, JL, David L, Bourgeat-Lami E. Aqueous dispersions of silanefunctionalized laponite clay platelets. A first step toward the elaboration of water-based polymer/clay nanocomposites. Langmuir. 2004:1564-1571.

6. Ruggerone R, Plummer CJ, Herrera NN, Bourgeat-Lami E, Manson JA. E. Highly filled polystyrene-laponite nanocomposites prepared by emulsion polymerization. Eur. Polym. J. 2009:45(3):621-629.

7. Negrete-Herrera N, Putaux, J.-L, Bourgeat-Lami E. Synthesis of polymer/Laponite nanocomposite latex particles via emulsion polymerization using silylated and cation-exchanged laponite clay platelets. Prog. Solid State Chem. 2006:34(2):121-137. 
8. Bourgeat-Lami E, Herrera NN, Putaux JL, Perro A, Reculusa S, Ravaine S, Duguet E. Designing organic/inorganic colloids by heterophase polymerization. Macromol. Symp. 2007:248:213-226.

9. Bourgeat-Lami E, Guimarães TR, Pereira AMC, Alves GM, Moreira JC, Putaux JL, dos Santos AM. High solids content, soap-free, film-forming latexes stabilized by Laponite clay platelets. Macromol. Rapid Commun. 2010:31:1874-1880.

10. Teixeira RF, McKenzie HS, Boyd AA, Bon SA. Pickering emulsion polymerization using laponite clay as stabilizer to prepare armored "soft" polymer latexes. Macromol. 2011:44 (18):7415-7422.

11. Soh SK, Sundberg DC. Diffusion-Controlled Vinyl Polymerization. III. Free volume parameters and diffusion-controlled propagation. J. Polym. Sci. Polym. Chem. 1982:20(5):1331-1344.

12. Casey BS, Morrison BR, Maxwell IA, Gilbert RG, Napper DH. Free radical exit in emulsion polymerization. I. Theoretical model. J. Polym. Sci. A Polym. Chem. 1994:32(4):605-630.

13. McAuliffe C. Solubility in water of paraffin, cycloparaffin, olefin, acetylene, cycloolefin, and aromatic hydrocarbons1. J. Phys. Chem. 1966:70(4):1267-1275.

14. Colombié D, Landfester K, Sudol ED, El-Aasser MS. Competitive adsorption of the anionic surfactant SLS and the nonionic surfactant triton X-405 on polystyrene latex particles. Langmuir. 2000:16(21):7905-7913.

15. Adams M, Trau M, Gilbert R, Napper D, Sangster D. The entry of free radicals into polystyrene latex particles. Aust. J. Chem. 1988:41(12):1799-1813.

16. Kusters JMH, Napper DH, Gilbert RG, German AL. Kinetics of particle growth in emulsion polymerization systems with surface-active initiators. Macromolecules. 1992:25(256):7043-7050.

17. Colombié D, Sudol ED, El-Aasser MS. Effect of a mixed anionic-nonionic system of surfactants on the entry and exit of free radicals into polystyrene particles. Macromolecules 2000:33(12):43474353. 
18. Wang X, Boya B, Sudol ED, El-Aasser MS. Effect of a reactive surfactant and its polymeric counterpart on the kinetics of seeded emulsion polymerization of styrene. Macromol. 2001:34(26):8907-8912.

19. Coen EM, Lyons RA, Gilbert RG. Effects of Poly(acrylic Acid) Electrosteric stabilizer on entry and exit in emulsion polymerization. Macromol. 1996:29(15):5128-5135.

20. Cheong IW, Kim JH. Effects of surface charge density on emulsion kinetics and secondary particle formation in emulsifier-free seeded emulsion polymerization of methyl methacrylate. Coll. \& Polym.Sci. 1997:275(8):736-743.

21. Vorwerg L, Gilbert RG. Electrosteric Stabilization with Poly(Acrylic) Acid in emulsion polymerization: Effect on kinetics and secondary particle formation. Macromol. 2000:33 (18):66936703.

22. Leemans L, Jérôme R, Teyssié P. Diffusive radical entry as the rate-determining step in amphiphilic block polyelectrolyte mediated emulsion polymerization. Macromol. 1998:31:(17):5565-5571.

23. Tawari SL, Koch DL, Cohen C. Electrical double-layer effects on the Brownian diffusivity and aggregation rate of laponite clay particles. J. Colloid Interface Sci. 2001:240:54-66.

24. Ruzicka B, Zulian L, Ruocco G. More on the phase diagram of Laponite. Langmuir. 2006:22:11061111.

25. Brunier B, Sheibat-Othman N, Chevalier Y, Bourgeat-Lami E. Partitioning of Laponite clay platelets in Pickering emulsion polymerization. Langmuir. 2016:32(1):112-124.

26. Brunier B, Sheibat-Othman N, Chniguir M, Chevalier Y, Bourgeat-Lami E. Investigation of four different Laponite clays as stabilizers in Pickering emulsion polymerization. Langmuir. 2016:32 (24):6046-6057. 
27. Finsy R, Particle Sizing by Quasi-Elastic Light Scattering. Adv. Colloid Interface Sci. 1994:52:79_ 143.

28. Ruf H. Data accuracy and resolution in particle sizing by dynamic light scattering. Adv. Colloid Interface Sci. 1993:46:333-342.

29. Anderson W, Kozak D, Coleman VA, Jämting ÅK, Trau M. A comparative study of submicron particle sizing platforms: Accuracy, precision and resolution analysis of polydisperse particle size distributions. J. Colloid Interface Sci. 2013:405:322-330.

30. Min KW, Ray WH. On the mathematical modeling of emulsion polymerization reactors. J. Macromol. Sci, Part C: Polym. Reviews. 1974:11(2):177-255.

31. Smith WV, Ewart RH. Kinetics of emulsion polymerization. J. Chem. Phys. 1948:16(6):592-599.

32. Harkins WD. A General theory of the mechanism of emulsion polymerization. J. Am. Chem. Soc. 1947:69(6):1428-1444.

33. Lovell, El-Aasser MS. Emulsion polymerization and emulsion polymers, John Wiley and Sons.; Chichester, 1997.

34. Vale H, McKenna TF. Particle formation in vinyl chloride emulsion polymerization: Reaction Modeling. Ind. Eng. Chem. Res. 2009:48(11):5193-5210.

35. Sajjadi S. Population balance modeling of particle size distribution in monomer-starved semibatch emulsion polymerization. AIChE J. 2009:55(12):3191-3205.

36. Ballard MJ: Gilbert RG: Napper DH. Improved methods for dolving the Smith — Ewart rquations in the dteady dtate. J. Polym. Sci. B Polym. Lett. 1981:19(11):533-537.

37. Smoluchowski M. Versuch einer mathematischen Theorie der Koagulationskinetik kolloider Lösungen. Pisma Mariana Smoluchowskiego. 1927:2(1):595-639. 
38. Thickett SC, Gilbert RG. Emulsion polymerization: State of the art in kinetics and mechanisms. Polym. 2007:48(24):6965-6991.

39. Ugelstad J, Hansen FK. Kinetics and mechanism of emulsion polymerization. Rubber Chem. Tech. 1976:49(3):536-609.

40. Herrera-Ordóñez J, Olayo R. On the kinetics of styrene emulsion polymerization above CMC. I. A mathematical model. J. Polym. Sci. A Polym. Chem. 2000:38(12):2201-2218.

41. Hernandez HF, Tauer K. Brownian dynamics simulation studies on radical capture in emulsion polymerization. Macrom. Symposia. 2007:259:274-283.

42. Nomura M, Tobita H, Suzuki K. Emulsion polymerization: Kinetic and mechanistic aspects. In Polymer Particles; Okubo, M., Ed.; Advances in Polymer Science; Springer Berlin Heidelberg, 2005:1-128.

43. Coen EM, Gilbert RG, Morrison BR, Leube H, Peach S. Modelling particle size distributions and secondary particle formation in emulsion polymerisation. Polym. 1998:39(26):7099-7112.

44. Harada M, Nomura M, Kojima H, Eguchi W, Nagata S. Rate of emulsion polymerization of styrene. J. Appl. Polym. Sci. 1972:16(4):811-833.

45. Gardon JL. Emulsion Polymerization. I. Recalculation and extension of the Smith-Ewart theory. J. of Polym. Sci. P. A-1: Polym. Chem. 1968:6(3):623-641.

46. Penboss I, Gilbert R, Napper D. Entry rate coefficients in emulsion polymerization systems. J. Chem. Soc., Faraday Trans. 1 Phys Chem. Condensed Phases. 1986:82(7):2247-2268.

47. Maxwell IA, Morrison BR, Napper DH, Gilbert RG. Entry of free radicals into latex particles in emulsion polymerization. Macromol. 1991:24(7):1629-1640.

48. Dong Y, Sundberg DC. Radical entry in emulsion polymerization: Estimation of the critical length of entry radicals via a simple Lattice model. Macromol. 2002:35(21):8185-8190. 
49. Gilbert R. Emulsion Polymerization, Academic Press san Diego, 1995.

50. Yeliseyeva VI, Zuikov AV. Emulsion polymerization of polar monomers. Polym. Sci. U.S.S.R 1977:19(11):3021-3031.

51. Hernandez HF, Tauer K. Radical desorption kinetics in emulsion polymerization. 1. Theory and simulation. Ind. Eng. Chem. Res. 2008:47(24):9795-9811.

52. Harada M, Nomura M, Eguchi W, Nagata S. Studies of the effect of polymer particles on emulsion polymerization. J. of Chem. Eng. of Japan. 1971:4(1):54-60.

53. Vanzo E, Marchessault RH, Stannett V. The solubility and swelling of latex particles. J. Colloid Sci. 1965:20(1):62-71.

54. Asua JM, De La Cal JC. Entry and exit rate coefficients in emulsion polymerization of styrene. J. Appl. Polym. Sci. 1991:42(7):1869-1877.

55. Liotta V, Georgakis C, Sudol ED, El-Aasser MS. Manipulation of competitive growth for particle size control in emulsion polymerization. Ind. Eng. Chem. Res. 1997:36(8):3252-3263.

56. Brunier B, Sheibat-Othman N, Othman S, Chevalier Y, Bourgeat-Lami E. Modelling particle growth under saturated and starved conditions in emulsion polymerization. Can. J. Chem. Eng. 2017:95(2):208-221.

57. Chang KHS, Litt MH, Nomura, M. The reinvestigation of vinyl acetate emulsion polymerization (I) -The rate of polymerization. In Emulsion Polymerization of Vinyl Acetate; El-Aasser, M. S., Vanderhoff, J. W., Eds.; Springer Netherlands, 1981:89-136.

58. Morrison BR, Casey BS, Lacik I, Leslie GL, Sangster DF, Gilbert RG, Napper DH. Free radical exit in emulsion polymerization. II. Model discrimination via experiment. J. Polym. Sci. A Polym. Chem. 1994:32(4):631-649. 
59. Asua JM, Sudol ED, El-Aasser MS. Radical desorption in emulsion polymerization. J. Polym. Sci. A Polym. Chem. 1989:27:(12):3903-3913.

60. Ghielmi A, Cuccato D, Storti G. Particle state dependent radical desorption and its effect on the kinetics of emulsion polymerization. Ind. Eng. Chem. Res. 2014:53:(22):9049-9057.

61. Brooks BW, Makanjuola BO. Measurements of the rate of radical desorption from polymer latices during emulsion polymerisation. J. Chem. Soc., Faraday Trans. 1 1981:77(11):2659-2667. 